\title{
The Global Distribution of Thermospheric Odd Nitrogen for Solstice Conditions During Solar Cycle Minimum
}

\author{
J.-C. GÉRARD \\ Institut d'Astrophysique Université de Liège \\ R. G. ROBLE \\ National Center for Atmospheric Research \\ D. W. Rusch and A. I. Stewart \\ Laboratory for Atmospheric and Space Physics, University of Colorado
}

\begin{abstract}
A two-dimensional model of the minor neutral constituents $N\left({ }^{2} \mathrm{D}\right), \mathrm{N}\left({ }^{4} \mathrm{~S}\right)$, and $\mathrm{NO}$ from 70 to $360 \mathrm{~km}$ is formulated and used to investigate the global distributions of these species for December solstice conditions during solar cycle minimum. For background properties the zonally averaged circulation, temperature, and compositional structure of major neutral constituents in the thermosphere are obtained from the coupled dynamical chemical model calculations of Roble and Kasting (this issue). Transport of the minor neutral constituents by both the meridional and vertical circulation and vertical molecular and eddy diffusion are considered in the model. The calculated distributions of the minor neutral constituents for solar ionization only and for solar plus auroral ionization are considered. The results show that the summer-to-winter pole meridional circulation transports both $\mathrm{NO}$ and $\mathrm{N}\left({ }^{4} \mathrm{~S}\right)$ across the solar terminator into the polar night region where there is a downward vertical transport toward the mesosphere. The calculated latitudinal distribution of NO in the lower thermosphere for the solar-ionization-only case does not agree with the latitudinal NO distribution usually measured by the Atmosphere Explorer satellites. To obtain agreement between the calculated and observed structure, it is necessary to include ionization and dissociation sources due to auroral particle precipitation. The temperature and compositional structure and the circulation changes caused by high-latitude heating and the particle-induced production of $\mathrm{N}\left({ }^{2} \mathrm{D}\right)$ and $\mathrm{N}\left({ }^{4} \mathrm{~S}\right)$ all combine to bring the calculated NO structure into better agreement with observations. The choice of the eddy diffusion coefficient critically controls the downward flow of thermospheric nitric oxide into the mesosphere. The model shows that the odd nitrogen densities at high winter latitudes are entirely controlled by particle precipitation and transport processes.
\end{abstract}

\section{INTRODUCTION}

Nitric oxide was first observed in the earth's upper atmosphere by measuring resonantly scattered sunlight in the $y$ bands [Barth, 1974]. This technique has provided a wealth of observational data relating to the altitude distribution of NO [Meira, 1970; Tisone, 1973; Tohmatsu and Iwagami, 1976; Baker et al., 1977; Trinks et al., 1978; Thomas, 1978; Beran and Bangert, 1979] and the characteristics of its global distribution [Rusch, 1973; Rusch and Barth, 1975; Stewart and Cravens, 1978; Cravens and Stewart, 1978; Cravens et al., 1979; Cravens, 1981]. Massie [1980] derived the nitric oxide vertical distribution at twilight by measuring the absorption of the ultraviolet solar radiation at the wavelength of the $(1,0) \delta$ band. Measurements of NO density profiles in the upper stratosphere and lower mesosphere by chemiluminescent techniques are less frequent [Mason and Horvath, 1976; Horvath and Mason, 1978]. Ion composition measurements of the $D$ and $E$ region have also been used to infer the ambient NO density [Swider, 1978; Golshan and Sechrist, 1975].

The vertical distribution of nitric oxide in the mid-latitude region between 50 and $200 \mathrm{~km}$ is characterized by a density

Copyright 1984 by the American Geophysical Union.

Paper number 3A1751.

0148-0227/84/003A-1751\$05.00 of 1-3 $\times 10^{8}$ molecules $\mathrm{cm}^{-3}$ at $50 \mathrm{~km}$; a decrease in density, with a scale height close to the mixing scale height, to a minimum of a few times $10^{6}$ to a few times $10^{7} \mathrm{~cm}^{-3}$ at $80-85$ $\mathrm{km}$; a relative maximum of a few times $10^{7}$ to a few times $10^{8}$ $\mathrm{cm}^{-3}$ at $95-115 \mathrm{~km}$; and an upper thermosphere scale height characteristic of a constituent in diffusive equilibrium. As indicated, the measured profiles exhibit large spatial, seasonal, and diurnal variations.

Global characteristics of nitric oxide distributions in the lower thermosphere and upper mesosphere indicate large latitudinal and seasonal variations and geomagnetic effects. Larger amounts of NO are seen in the polar regions than at mid-latitudes [Rusch and Barth, 1975; Cravens and Stewart, 1981]; the amount of NO at high latitudes responds to geomagnetic activity [Gérard and Barth, 1977; Stewart and Cravens, 1978], and there is evidence of NO transport from high to low latitudes at times of enhanced geomagnetic activity [Cravens and Stewart, 1978]. Furthermore, the magnitude of the latitude gradient depends upon the $A p$ index; the greater the $A p$ value, the larger the gradient. Geisler and Dickinson [1968] have shown that vertical velocities of the magnitude associated with either planetary waves or with a mean meridional circulation can transport a substantial amount of nitric oxide from the thermosphere into the $70-85 \mathrm{~km}$ region.

Theoretical investigations of the chemistry of NO in the lower thermosphere [Norton and Barth, 1970; Strobel et al., 1970; Rusch, 1973] identified the reaction of metastable 
atomic nitrogen and molecular oxygen as the major source of NO,

$$
\mathrm{N}\left({ }^{2} \mathrm{D}\right)+\mathrm{O}_{2} \rightarrow \mathrm{NO}+\mathrm{O}
$$

and the reaction of ground-state atomic nitrogen with NO as the major chemical loss:

$$
\mathrm{N}\left({ }^{4} \mathrm{~S}\right)+\mathrm{NO} \rightarrow \mathrm{N}_{2}+\mathrm{O}
$$

Thus the amount of NO present depends on the relative concentrations of $\mathrm{N}\left({ }^{2} \mathrm{D}\right)$ with respect to $\mathrm{N}\left({ }^{4} \mathrm{~S}\right)$ and the reaction rate coefficients for reactions (1) and (2). The extended theoretical picture is more complicated as $\mathbf{N}$ and NO are subject to transport processes and the chemical system involved in the production and loss of atomic nitrogen is complex. The intricacies of this system have been explored by Oran et al. [1975], Rusch et al. [1975], Cravens et al. [1979], Rusch and Sharp [1981], and Frederick and Orsini [1982], in the mid-latitude ionosphere, and by Hyman et al. [1976], Gérard and Barth [1977], Roble and Rees [1977], Gérard and Rusch [1979], Rees and Roble [1979], and Rusch and Gérard [1980] in the high-latitude disturbed ionosphere. Solomon et al. [1982a, b] examined the latitudinal and seasonal variations of the NO distribution by using a two-dimensional chemical-transport model from the ground to $110 \mathrm{~km}$. More recently, Garcia and Solomon [1983] used a two-dimensional time-dependent model to study the zonally averaged structure of the middle atmosphere (16-116 km), allowing interactions among dynamics, radiation and photochemistry.

Models that include the known chemistry and solve the one-dimensional continuity equations have been successful in reproducing the general features of the measured nitric oxide vertical density profiles in the thermosphere and mesosphere. However, these models cannot account for the variation of the NO profile with latitude as derived from satellite data. In a critical comparison of a one-dimensional model to observations from the Atmosphere Explorer satellite, Cravens et al. [1979] concluded that only under extremely quiet geomagnetic conditions $(A p \leq 6)$ were the results of a one-dimensional model comparable to the measured nitric oxide latitude gradients in the low and midlatitude $E$ region. They speculated that horizontal transport was important and that a high-latitude source of NO must exist and be related to the geomagnetic activity. The fact that particle ionization of the earth's atmosphere could result in enhanced NO densities was demonstrated experimentally by measurements of enhanced $\mathrm{NO}^{+} / \mathrm{O}_{2}{ }^{+}$ratios [Donahue et al., 1970; Narcisi and Swider, 1976] and large NO densities [Rusch and Barth, 1975; Sharp, 1978; Witt et al., 1981] in the auroral zone. Theoretical results [Hyman et al., 1976; Gérard and Barth, 1977; Roble and Rees, 1977; Rees and Roble, 1979; Gérard and Rusch, 1979] indicated that large localized enhancements of NO over ambient densities were possible under or after particle bombardment. Consequently, there is a wealth of observations indicating the influence of particle ionization and, possibly, meridional winds on the global nitric oxide distribution.

The characteristics of the zonal mean thermospheric circulation have been studied by Dickinson et al. [1975, 1981] for equinox and by Dickinson et al. [1977, 1981] for solstice conditions. The seasonal variations and the solar cycle effects were described by Roble et al. [1977]. These studies have shown that during the solstice period a summer-towinter mean meridional wind exists, but the circulation reverses in the winter $F$ region if significant-Joule heating is present at high latitudes. The conclusions of these models have been largely confirmed by the measurements of meridional winds deduced from observations of the $630.0-\mathrm{nm}$ airglow Doppler shift [Hernandez and Roble, 1976a, b] and by incoherent scatter radar measurements [Emery, 1978a, $b$; Babcock and Evans, 1979; Oliver, 1980]. The coupling between zonal mean dynamics and composition in the lower thermosphere was studied by Kasting and Roble [1981] and Roble and Kasting [this issue], and their results are used as background properties for our calculations, as described in a later section.

The importance of enhanced NO thermospheric densities as a sink for stratospheric ozone was suggested by Crutzen [1979]. Solomon [1981] and Solomon et al. [1982a] used a two-dimensional photochemical-transport model from the ground to $110 \mathrm{~km}$ to study the transport of thermospheric NO toward lower altitudes and Garcia and Solomon [1983] used a coupled, zonally averaged chemical-radiational-dynamic model to study the transport process of NO in more detail. The results of these studies have shown that the NO produced in the thermosphere and by auroral processes can be transported downward to the stratosphere, particularly at high latitudes during polar winter. This process provides a coupling between the upper and lower atmosphere that may play a significant role in the photochemistry of odd nitrogen and odd oxygen in the stratosphere. A recent paper by Frederick et al. [1983] also points out that thermospheric NO has an influence on the mesospheric and stratospheric NO solar photodissociation rates in the $\delta(0,0)$ and $\delta(1,0)$ bands, and this radiative interaction may be an important coupling mechanism between the thermosphere and middle atmosphere.

Equatorward transport of NO by winds and diffusion from the polar to the mid-latitude winter regions is believed to be partly responsible for the $D$ region winter anomaly [e.g., Sechrist, 1967; Solomon et al., 1982b]. Enhancements of the $D$ region electron densities occasionally observed during winter have been attributed to the presence of large amounts of nitric oxide in the mesosphere. Although there is observational evidence in favor of strong horizontal and vertical winds in the auroral thermosphere during magnetically disturbed periods, it is not clear whether the speed and the direction of the meridional component are adequate to carry NO to mid-latitude regions. To investigate these problems, we developed a model to quantitatively describe the global effect of horizontal and vertical transport on odd nitrogen densities in the earth's thermosphere and mesosphere. In an initial treatment, Roble and Gary [1979] showed that the effect of horizontal transport due to winds on aurorally produced nitric oxide could be locally important. Gérard et al. [1980] gave a description of an early version of the code described here and showed preliminary calculations of the two-dimensional distributions of $\mathrm{NO}, \mathrm{N}\left({ }^{4} \mathrm{~S}\right)$, and $\mathrm{N}\left({ }^{2} \mathrm{D}\right)$ for the case of equinox and no thermospheric winds. Rusch et al. [1981] presented initial results that gave the minor neutral constituent distributions, including transport by winds, during the solstice period, as specified by the chemical-dynamical model of Kasting and Roble [1981].

In this paper a two-dimensional model of odd nitrogen in the thermosphere and upper mesosphere is described. The 
TABLE 1. Odd Nitrogen Chemistry

\begin{tabular}{|c|c|c|}
\hline Reaction & Rate Coefficient* & Source \\
\hline $\begin{array}{l}\text { 1. } \mathrm{N}_{2}+e^{*} \rightarrow \mathrm{N}\left({ }^{4} \mathrm{~S}\right)+\mathrm{N}\left({ }^{2} \mathrm{D}\right)+e^{*} \\
\text { 2. } \mathrm{N}_{2}+h \nu \rightarrow \mathrm{N}\left({ }^{4} \mathrm{~S}\right)+\mathrm{N}\left({ }^{2} \mathrm{D}\right)\end{array}$ & $\begin{array}{l}J_{\infty}\left(\mathrm{N}_{2}\right)=1.1 \times 10^{-8} \mathrm{~s}^{-1} \\
f\left({ }^{2} \mathrm{D}\right)=0.5\end{array}$ & $\begin{array}{l}\text { Roble [1976] } \\
\text { Oran et al. [1975] } \\
\text { Zipf et al. }[1980]\end{array}$ \\
\hline 3. $\mathrm{NO}+h \nu \rightarrow \mathrm{N}\left({ }^{4} S\right)+\mathrm{O}$ & $J_{\infty 0}(\mathrm{NO})=3.95 \times 10^{-6} \mathrm{~s}^{-1}$ & $\begin{array}{l}\text { Frederick and Hudson } \\
\text { [1979] }\end{array}$ \\
\hline $\begin{array}{l}\text { 4. } \mathrm{N}_{2}^{+}+\mathrm{O} \rightarrow \mathrm{NO}^{+}+\mathrm{N}\left({ }^{2} \mathrm{D}\right) \\
\text { 5. } \mathrm{O}_{2}^{+}+\mathrm{NO} \rightarrow \mathrm{NO}^{+}+\mathrm{O}_{2} \\
\text { 6. } \mathrm{O}_{2}^{+}+\mathrm{N}\left({ }^{4} \mathrm{~S}\right) \rightarrow \mathrm{NO}^{+}+\mathrm{O} \\
\text { 7. } \mathrm{NO}^{+}+e \rightarrow \mathrm{N}\left({ }^{2} \mathrm{D},{ }^{4} \mathrm{~S}\right)+\mathrm{O}\end{array}$ & $\begin{array}{l}1.4 \times 10^{-10}(T / 300)^{-0.44} \\
4.4 \times 10^{-10} \\
1.8 \times 10^{-10} \\
4.2 \times 10^{-7}(300 / T e)^{0.85} \\
f\left({ }^{2} \mathrm{D}\right)=0.75\end{array}$ & $\begin{array}{l}\text { McFarland et al. }[1974] \\
\text { Lindinger et al. }[1974] \\
\text { Goldan et al. }[1966] \\
\text { Torr et al. }[1976] \\
\text { Kley et al. }[1977]\end{array}$ \\
\hline $\begin{array}{l}\text { 8. } \mathrm{N}\left({ }^{4} \mathrm{~S}\right)+\mathrm{O}_{2} \rightarrow \mathrm{NO}+\mathrm{O} \\
\text { 9. } \mathrm{N}\left({ }^{4} \mathrm{~S}\right)+\mathrm{NO} \rightarrow \mathrm{N}_{2}+\mathrm{O} \\
\text { 10. } \mathrm{N}\left({ }^{2} \mathrm{D}\right)+\mathrm{O}_{2} \rightarrow \mathrm{NO}+\mathrm{O} \\
\text { 11. } \mathrm{N}\left({ }^{2} \mathrm{D}\right)+\mathrm{O} \rightarrow \mathrm{N}\left({ }^{4} \mathrm{~S}\right)+\mathrm{O}\end{array}$ & $\begin{array}{l}4.4 \times 10^{-12} \exp (-3220 / T) \\
2.1 \times 10^{-11} \\
6 \times 10^{-12} \\
5 \times 10^{-13}\end{array}$ & $\begin{array}{l}\text { Phillips and Schiff [1962] } \\
\text { Lin and Kaufman [1971] } \\
\text { Frederick and Rusch } \\
\text { [1977] }\end{array}$ \\
\hline
\end{tabular}

*Rates are in units of $\mathrm{cm}^{-3} \mathrm{~s}^{-1}$ unless otherwise noted, $f\left({ }^{2} \mathrm{D}\right)$ indicates branching ratio for the reaction, $J_{\infty}(\mathrm{NO})$ is the photodissociation rate of $\mathrm{NO}$ at zero optical depth by sunlight.

global distributions of nitric oxide and atomic nitrogen are calculated for the solstice period for quiet and moderate magnetic activity during the solar minimum period. The effect of thermospheric transport by winds is investigated as well as the importance of particle-induced ionization in the auroral zones. The background neutral atmosphere temperature and wind field are taken from the Kasting and Roble [1981] model modified to include the high-latitude heat sources consistent with the auroral electron impact ionization [Roble and Kasting, this issue]. The results are compared with rocket and satellite measurements, and the sensitivity of the model to eddy diffusion and neutral winds is investigated. Implications of the present calculations on needs for future experimental and modeling work are discussed. Finally, downward fluxes of NO into the mesosphere are given, and their importance for stratospheric ozone are discussed in view of the recent calculations by Solomon et al. [1982a, b].

\section{THE ModeL}

In polar coordinates the two-dimensional continuity equation for a minor constituent $\boldsymbol{n}_{i}$ moving through a background gas may be written in the form:

$$
\frac{\partial n_{i}}{\partial t}=p_{i}-L_{i} n_{i}-\frac{\partial \phi_{i}}{\partial r}-\frac{1}{r^{2}} \frac{\partial\left(r^{2} w\right)}{\partial r}-\frac{1}{r \sin \theta} \frac{\partial(v \sin \theta)}{\partial \theta}
$$

where $r$ and $\theta$ are the geocentric altitude and the colatitude, respectively; $P_{i}$ is the chemical production rate of $n_{i} ; L_{i}$ is its loss frequency; $v$ and $w$ are the meridional and vertical winds, respectively; and $\phi_{i}$ is the vertical flux due to molecular and eddy diffusion. The equation for the vertical flux is

$$
\begin{aligned}
\phi_{i}=-D_{i}\left(\frac{n_{i}}{H_{i}}+\frac{\partial n_{i}}{\partial r}+\frac{n_{i}}{T}\right. & \left.\frac{\partial T}{\partial r}\right) \\
& -K\left(\frac{n_{i}}{\bar{H}}+\frac{\partial n_{i}}{\partial r}+\frac{n_{i}}{T} \frac{\partial T}{\partial r}\right)
\end{aligned}
$$

where $D_{i}$ and $K$ are the molecular and eddy diffusion coefficients, respectively; $\bar{H}$ is the background atmospheric scale height; $\boldsymbol{H}_{i}$ is the diffusive equilibrium scale height of $\boldsymbol{n}_{i}$; and $T$ is the neutral temperature.

By combining (3) and (4), a second-order partial differential equation is obtained for the density of $\mathrm{N}\left({ }^{4} \mathrm{~S}\right)$ and NO. The two coupled partial differential equations are solved simultaneously by a code developed by Roble and Gary [1979]. The finite difference scheme for (3) is a splitting method developed by John Gary (private communication, 1982).

A two-dimensional grid extends from pole to pole in $5^{\circ}$ intervals of latitude and from 70 to $356 \mathrm{~km}$ in variable altitude steps. The step sizes at each level are approximately one third of the local atmospheric scale height. The grid is the same as that used by Kasting and Roble [1981] so that the output variables of $\mathrm{O}, \mathrm{O}_{2}$, and $\mathrm{N}_{2}$ winds and temperature from their model can be used to describe the background properties needed for our two-dimensional minor neutral constituent model.

The adopted chemical reactions, ionization and dissociation reactions, and their rates are taken from Cravens et al. [1979] with few exceptions. Various reactions in the model and their rates are given in Table 1 . A revised rate for reaction (8) in Table 1 is adopted to agree with the $N A S A$ [1979] recommendation. A $50 \%$ yield of $N\left({ }^{4} S\right)$ and $N\left({ }^{2} D\right)$ from $\mathrm{N}_{2}$ photodissociation is adopted. A $60 \%$ yield of $N\left({ }^{2} \mathrm{D}\right)$ production by electron impact dissociation of $\mathrm{N}_{2}$ is used, which is intermediate between the value of $50 \%$ deduced by Zipf et al. [1980] and 70\% used by Cravens et al. [1979].

In addition to photoionization processes the model also considers the effects caused by particle precipitation in the auroral zone. The spatial distribution of the total ionization rate by energetic electrons in the aurora is parameterized by a vertical Chapman profile and a Gaussian horizontal distribution:

$q(z, \theta)=q_{0} \exp \left[1-F(z)-e^{-F(z)}\right] \exp \left[-\left(\frac{\theta-\theta_{0}}{\Delta \theta}\right)^{2}\right]$

with

$$
F(z)=\frac{z-z_{0}}{H}
$$

where $q_{0}$ is the maximum ionization rate at altitude $z_{0}, H$ the topside scale height, and $\Delta \theta$ the characteristic latitudinal 
width of the auroral zones. This distribution is the same as that used by Roble and Kasting [this issue] for determining the thermospheric response of composition and dynamics to auroral particle precipitation. The relationship between the ionization rate and the particle heating term $Q_{p}$ is

$$
Q_{p}(z, \theta)=1.602 \times 10^{-12} \triangle E \varepsilon q(z, \theta) \text { ergs } \mathrm{cm}^{-3} \mathrm{~s}^{-1}
$$

where $\triangle E$ the mean energy loss to create an electron-ion pair and $\varepsilon$ is the neutral gas heating efficiency to auroral particle precipitation. We adopt a value of $35 \mathrm{eV}$ for $\Delta E$ in air and 0.6 for $\varepsilon$ in the $E$ region [Singh and Gérard, 1982]. The individual ionization rates are derived from $q(z, \theta)$, as described by Gérard and Rusch [1979]. The value of $q_{0}$ in (5) is obtained by normalizing the integral of $Q_{p}$ over the planet to a specified global energy input, as discussed by Roble and Kasting [this issue].

The important odd nitrogen reactions are detailed in Table 1. All ion densities $\left[\mathrm{O}^{+}, \mathrm{O}_{2}^{+}, \mathrm{N}^{+}, \mathrm{N}_{2}^{+}, \mathrm{NO}^{+}\right.$, and $\left.\mathrm{O}^{+}\left({ }^{2} \mathrm{D}\right)\right]$ and the $N\left({ }^{2} \mathrm{D}\right)$ density are solved under the assumption of photochemical equilibrium. The $\mathrm{NO}$ and $\mathrm{N}\left({ }^{4} \mathrm{~S}\right)$ densities are subject to horizontal and vertical transport. The photochemical production and loss rates are evaluated at each time step, using the newly calculated odd nitrogen densities.

The two-dimensional model assumes diurnally averaged conditions, and the average values of photoreaction rates are calculated from

$$
\bar{I}=I(\bar{\theta}) \cdot C
$$

where $C$ is the fraction of day with solar zenith angle $\leq 90^{\circ}$, and $\bar{\theta}$ is the local average solar zenith angle during sunlight hours. The values of $\bar{\theta}$ correspond to a diurnally averaged effective column density

$$
\bar{\eta}=\overline{0.6 \eta_{\mathrm{O}}+\eta_{\mathrm{O}_{2}}+\eta_{\mathrm{N}_{2}}}
$$

with

$$
\eta_{\mathrm{i}}=n_{i} H_{i} C h(H / R, \theta)
$$

where $C h$ is the Chapman function, and the bar indicates a diurnal average. The solar flux for minimum levels of solar activity is used [Hinteregger, 1981], and the ionization rates are calculated according to Stewart [1970].

The temperature, composition, and circulation for solstice conditions during solar minimum that are used as background properties for our model calculation are obtained from the calculations of Roble and Kasting [this issue], and they will not be discussed here. Our calculations are made for the same three cases discussed by Roble and Kasting that include $(a)$ solar heating alone, $(b)$ solar plus high-latitude heating for quiet geomagnetic activity, and (c) solar plus high-latitude heating for moderate levels of geomagnetic activity. Using these background solutions, we calculate the steady state distributions of the minor neutral constituents $\mathrm{N}\left({ }^{2} \mathrm{D}\right), \mathrm{N}\left({ }^{4} \mathrm{~S}\right)$, and $\mathrm{NO}$ and compare these distributions with various observations. At the present time of model development there is no interaction between our minor neutral constituent model and the chemical-dynamic model of Roble and Kasting. Also, in our model we calculate the transport of the minor neutral constituents NO and $N\left({ }^{4} S\right)$ by vertical molecular and eddy diffusion and by the mean meridional circulation. We neglect a possible net zonal mean transport caused by day-night asymmetries that can be defined as correlations of the diurnal meridional wind with departures of NO and $\mathrm{N}\left({ }^{4} \mathrm{~S}\right)$ densities from their zonal mean values, respectively. Also, because of the nature of the zonally averaged model, we do not include the effects of offset geomagnetic poles.

Perhaps the greatest uncertainty in our model calculation lies in the specification of the altitude and latitude distribution of the turbulent eddy diffusion coefficient. The eddy diffusion coefficient effectively transports thermospheric NO downward into the mesosphere. The vertical profile of the eddy diffusion coefficient has been derived at various latitudes by a number of investigators. These profiles have been used in various one-dimensional models to study the vertical distributions of chemical species in the mesosphere and lower thermosphere. A review of recent results was given by Allen et al. [1981]. The only two-dimensional parameterization of the eddy diffusion coefficients for the mesosphere and lower theremosphere are those given by Ebel [1980], which are based on an analysis of wind variance and temperature data. The eddy coefficients have been parameterized for equinox and solstice conditions, and they have been used by Solomon [1981] and Solomon et al. [1982a] to study the transport of NO from the thermosphere to the lower atmosphere. These eddy diffusion coefficients are listed in Table 2 in Solomon et al. [1982a], and the solstice values of the vertical eddy diffusion coefficient that we use in our model calculations are contoured in Figure 1a. The maximum values of the eddy diffusion coefficient occur in the midlatitude winter hemisphere, and minimum values occur in the high-latitude summer hemisphere. We use these values in our calculation to be consistent with the study of Solomon et al. [1982a]. We, however, also consider an additional set of eddy diffusion coefficients (Figure $1 b$ )-the values used by Roble and Kasting [this issue]. All of our calculations are made with these two sets of eddy coefficient distributions, and the differences are discussed in the last section. The boundary conditions are zero flux for NO and $\mathrm{N}\left({ }^{4} \mathrm{~S}\right)$ through the upper boundary and through the lower boundary for $\mathrm{N}\left({ }^{4} \mathrm{~S}\right)$. The NO flux at $70 \mathrm{~km}$ is taken from the study by Solomon et al. [1982a], but the results are not essentially different from a zero flux conditions, except in the immediate vicinity of the lower boundary.

\section{RESULTS}

The results for all of the cases to be discussed are for solstice conditions during solar cycle minimum. The background properties for the minor neutral constituent calculation are the three cases presented by Roble and Kasting [this issue; hereinafter referred to as R-K]: (a) solar EUV heating and ionization alone, Figures 2 and 3 of R-K; (b) solar EUV and auroral heating ionization for quiet geomagnetic activity, Figures 4 and 5 of R-K; and (c) solar EUV and auroral heating and ionization for moderate geomagnetic activity, Figures 6 and 7 of R-K. The circulation, temperature, and composition solutions for each of these cases are used as background properties for the calculation of the minor neutral constituent number densities with the two-dimensional model described in the previous section. The numerical integration is run for $2.6 \times 10^{6}$ or 30 days where a quasisteady state is reached, except for case $(c)$, which is discussed later.

\section{a. Solar EUV Ionization Only}

For the first calculation the neutral winds are arbitrarily set equal to zero; therefore, this case represents a series of 


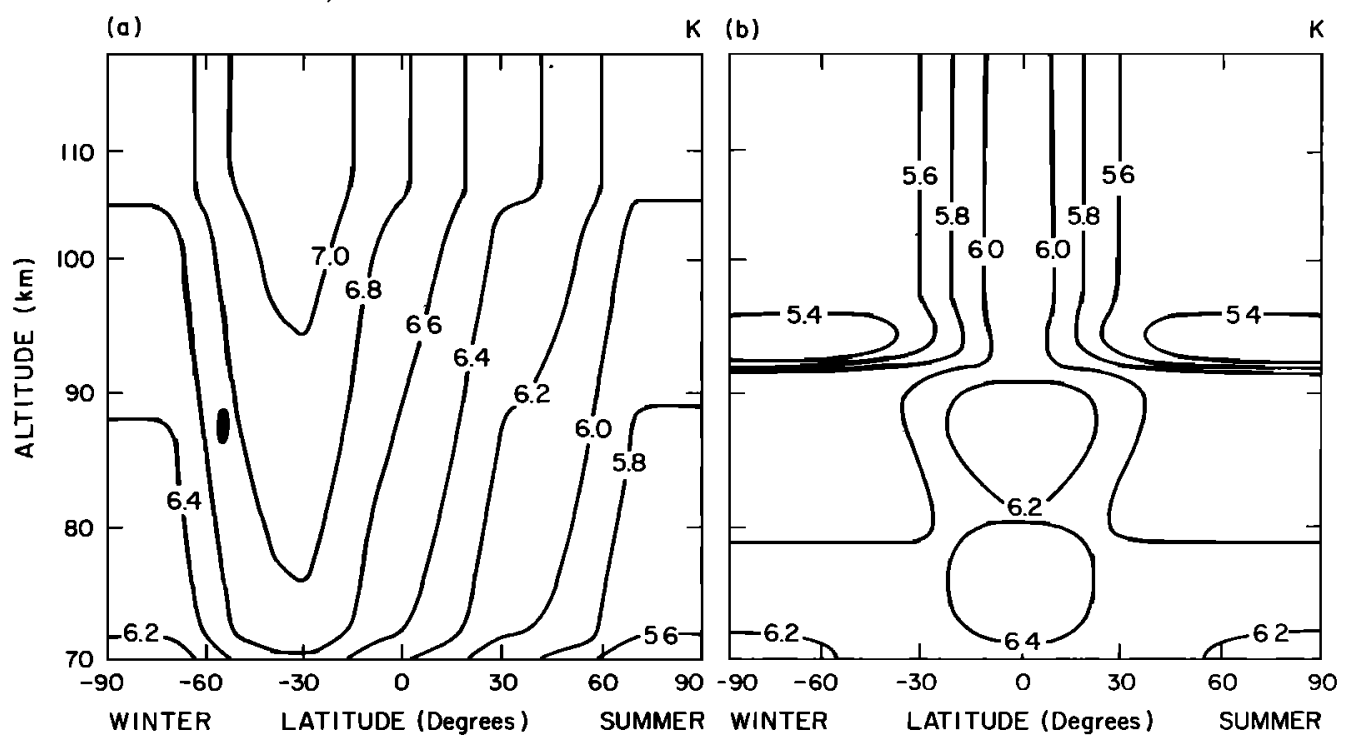

Fig. 1. Contours of $\log _{10}$ of eddy diffusion coefficients $\left(\mathrm{cm}^{-2} \mathrm{~s}^{-1}\right)$ used in the model calculations for solstice conditions: (a) values from Ebel [1980], (b) values used by Roble and Kasting [this issue].

one-dimensional solutions, as each latitude is independent of all others. The calculated distribution of $\mathrm{N}\left({ }^{2} \mathrm{D}\right)$ for the case of solar ionization only is shown in Figure 2. As discussed in the previous section, $\mathrm{N}\left({ }^{2} \mathrm{D}\right)$ is assumed to be in photochemical equilibrium. The maximum $\mathrm{N}\left({ }^{2} \mathrm{D}\right)$ density of $4.8 \times 10^{5}$ $\mathrm{cm}^{-3}$ occurs over the summer pole at an altitude of $220 \mathrm{~km}$. The latitudinal variation of $N\left({ }^{2} \mathrm{D}\right)$ is relatively small until the terminator is approached in the vicinity of $70^{\circ}$ latitude in the winter hemisphere. The $N\left({ }^{2} D\right)$ densities drop to small values in the polar night region where only a small ionization component caused by scattered EUV from the earth's geocorona is assumed.

The calculated distributions of NO and $N\left({ }^{4} S\right)$ for the nowind case are shown in Figures $3 a$ and $3 b$, respectively. The maximum NO density $\left(4 \times 10^{7} \mathrm{~cm}^{-3}\right)$ occurs at $110 \mathrm{~km}$ at $10^{\circ}$ latitude in the summer hemisphere. Above about $130 \mathrm{~km}$, the latitudinal variation of NO densities is small from the summer pole to about $30^{\circ}$ latitude in the winter hemisphere. The
NO densities are primarily determined by the background temperature and composition, the ionization rates, and vertical diffusion. There is a more rapid decrease from $-30^{\circ}$ latitude toward the winter pole, with an abrupt decrease at the solar terminator near $-70^{\circ}$ latitude. Below about $90 \mathrm{~km}$ the NO densities maximize in the winter hemisphere because of the larger solar zenith angles and smaller photodissociation rates. In the sunlit lower thermosphere a region of minimum NO densities of about $2 \times 10^{5} \mathrm{~cm}^{-3}$ occurs near 80 $\mathrm{km}$ in the summer polar region as a result of the strong predissociation of NO in the $\delta$ bands. This rapid destruction of NO effectively prevents any accumulation in the summer lower mesosphere, as discussed by Solomon et al. [1982a]. The abrupt decrease in NO density poleward of $70^{\circ}$ latitude in the winter hemisphere is due to the cutoff of solar ionizing radiation in the polar night region and the neglect of both horizontal transport and aurora particle ionization for this case.

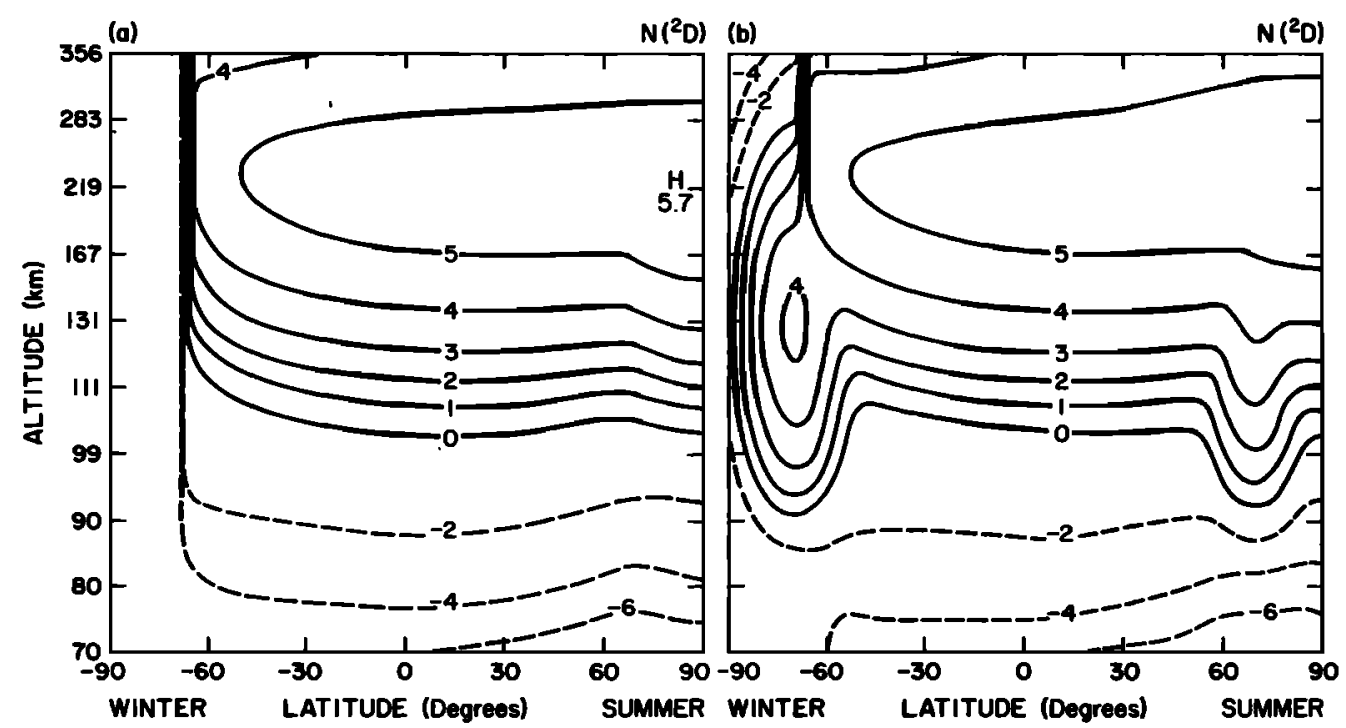

Fig. 2. Contours of $\log _{10}$ of zonally averaged $N\left({ }^{2} \mathrm{D}\right)$ number density $\left(\mathrm{cm}^{-3}\right)$ : (a) solar ultraviolet production only, (b) including high-latitude, particle-induced ionization and dissociation. 


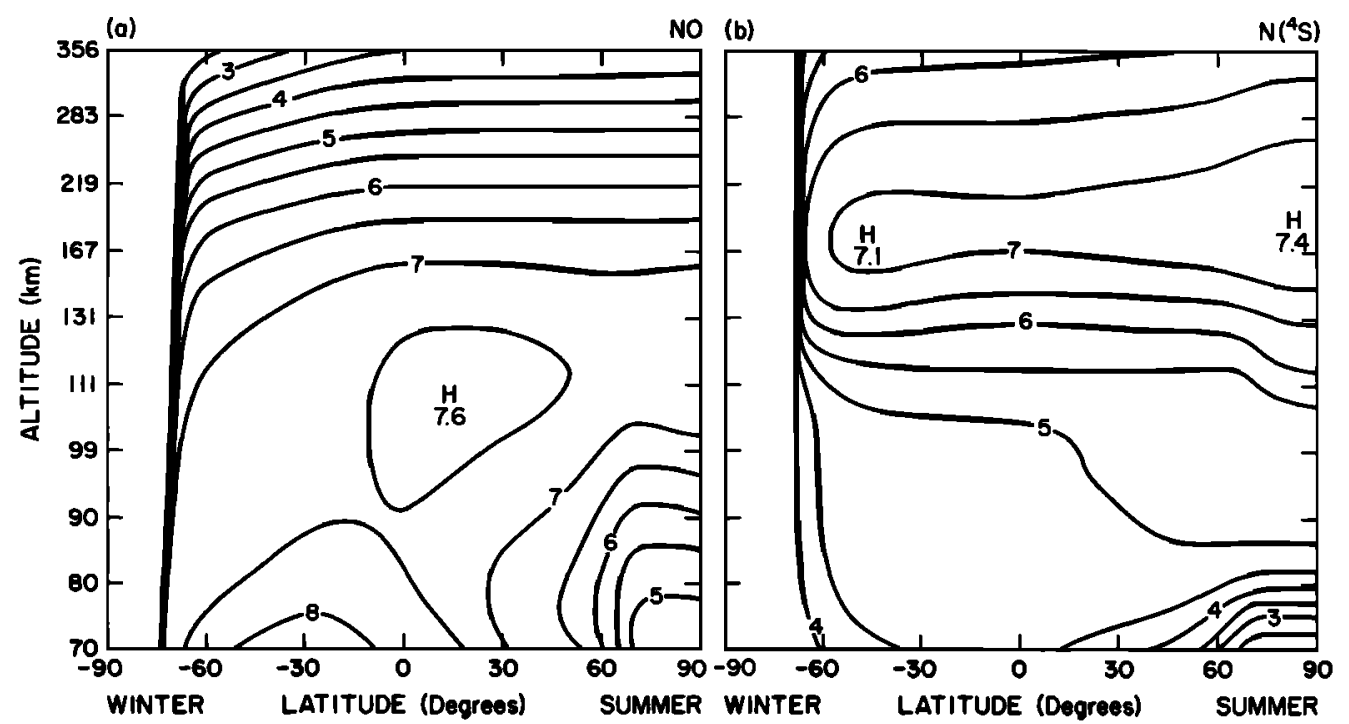

Fig. 3. Contours of $\log _{10}$ of zonally averaged densities of odd nitrogen $\left(\mathrm{cm}^{-3}\right)$ for solar ultraviolet production only and no wind: $(a)$ nitric oxide, $(b)$ atomic nitrogen.

The calculated distribution of $\mathrm{N}\left({ }^{4} \mathrm{~S}\right)$ for this case of no winds is shown in Figure $3 b$. Maximum $\mathrm{N}\left({ }^{4} \mathrm{~S}\right)$ densities occur near $170 \mathrm{~km}$ in the summer polar region, and the latitudinal variation is relatively small above $110 \mathrm{~km}$. In the lower thermosphere below $100 \mathrm{~km}$ a maximum is seen at the summer pole as a result of photolysis of NO, and the gradient is opposite that of NO because of the changing photolysis rate with latitude. Again there is an abrupt decrease in the $\mathbf{N}\left({ }^{4} \mathrm{~S}\right)$ density poleward of the terminator at $70^{\circ}$ latitude in the winter hemisphere.

The calculated NO and $\mathrm{N}\left({ }^{4} \mathrm{~S}\right)$ densities when winds are included in the calculation are shown in Figures $4 a$ and $4 b$, respectively. The primary effect of winds is to transport both NO and $N\left({ }^{4} S\right)$ across the terminator into the polar region with subsequent downward diffusion toward the lower thermosphere. Above about $120 \mathrm{~km}$, the winds smooth the compositional discontinuity at the terminator, and there is now a steady latitudinal decrease from the summer pole to the winter pole. In the sunlit region of the atmosphere there is very little noticeable effect of winds on the calculated NO densities, as seen in comparing Figures $3 a$ and $4 a$.

The calculated $\mathrm{N}\left({ }^{4} \mathrm{~S}\right)$ density for the case when winds are included is shown in Figure $4 b$. Above about $120 \mathrm{~km}, \mathrm{~N}\left({ }^{4} \mathrm{~S}\right)$ is transported by the meridional winds across the terminator into the polar night region. As with the NO densities there is a smooth latitudinal variation from the summer-to-winter pole. Below $120 \mathrm{~km}$, the $\mathrm{N}\left({ }^{4} \mathrm{~S}\right)$ density decreases rapidly as a result of the large NO densities that enhance the nitrogen loss rate through the "cannibalistic" reaction (9) in Table 1.

With respect to the no-wind case the NO maximum density decreases by about $10 \%$ in the summer hemisphere and increases by about $50 \%$ at $60^{\circ}$ latitude in the winter hemisphere because of the effect of meridional transport from the summer-to-winter polar region. At higher latitudes near the winter pole the NO vertical distribution exhibits no thermospheric peak because the NO flows downward without any chemical source or sink. NO densities below $100 \mathrm{~km}$ are at least one order of magnitude higher than the values in
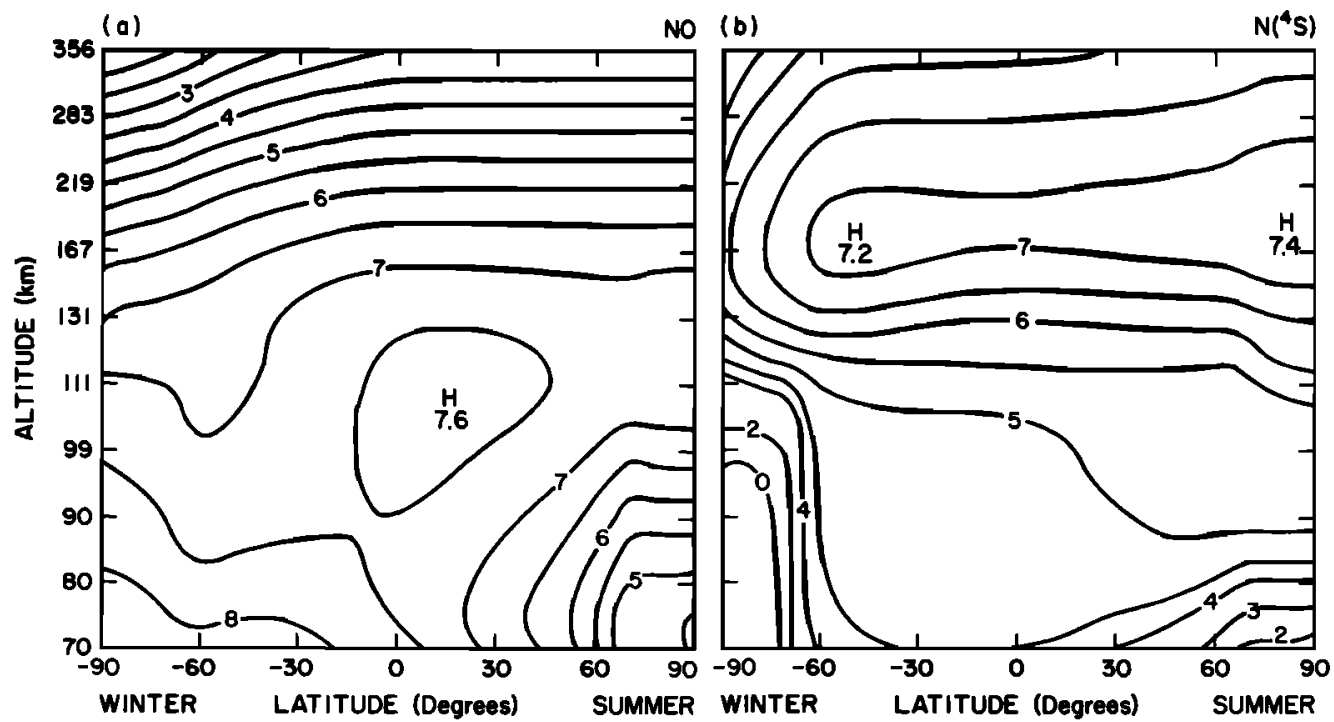

Fig. 4. Same as Figure 3, except that the zonally averaged wind field consistent with the composition and temperature fields is included in the transport equation. 


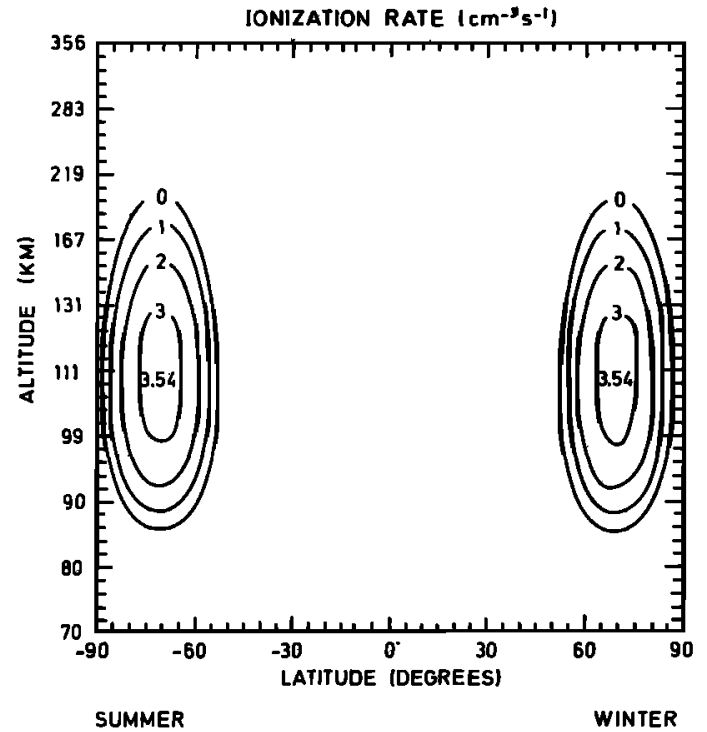

Fig. 5. Meridional distribution of the ionization rate $\left(\log _{10} q\right)$ adopted in the model for quiet conditions.

the sunlit regions. This is, again, a consequence of the absence of photodissociation of NO by solar UV radiation.

\section{b. Solar EUV and Quiet Auroral Ionization}

Roble and Kasting introduced a high-latitude ionization and heat source due to auroral processes in their model to determine its effect on the zonally averaged circulation, temperature, and compositional structure of the thermosphere for solstice conditions during solar cycle minimum. The total energy input for quiet geomagnetic activity was assumed to be $5 \times 10^{10} \mathrm{~W}$. The energy input was equally divided between Joule and particle heating. The Joule heating was assumed to be 2.5 times larger in the summer hemisphere, consistent with the studies for solstice conditions by Dickinson et al. [1977] and Roble et al. [1977]. This increase in heating in the summer hemisphere was attributed to the larger electrical conductivity. The ionization and heating caused by particle precipitation was equally divided between the summer and winter hemispheres. The parameterization of the auroral particle heating rate was discussed by $R-K$. The combined total ionization resulting from solar EUV and auroral particles is shown in Figure 5 and is derived from the particle heating distribution of $R-K$ by using expression (6). The maximum auroral ionization rate is $3.5 \times 10^{3}$ ions $\mathrm{cm}^{-3} \mathrm{~s}^{-1}$ at $110 \mathrm{~km}$ at the center of the auroral zone, corresponding to a particle energy flux of 0.53 ergs $\mathrm{cm}^{-2} \mathrm{~s}^{-1}$ and an $\mathrm{N}_{2}^{+}$391.4-nm column emission rate of about 600 to $700 \mathrm{R}$, which are rather moderate values roughly equivalent to IBC I aurora. This amount of energy can be compared with the average energy flux of about $2 \mathrm{ergs}^{-2}$ $\mathrm{s}^{-1}$ in the nightside oval derived by Torr et al. [1976] from a global study of the electron precipitation with the Atmosphere Explorer (AE-C) satellite. The AE-C measurements also show that during the daytime the particle energy flux decreases by more than an order of magnitude. Futhermore, they include all levels of magnetic activity between December 1973 and May 1975, whereas our value is intended to represent fairly quiet conditions only. Consequently, our adopted energy input is consistent with the measured global electron precipitation. The full width at half height of the Gaussian distribution in the auroral zone is assumed to be $8.3^{\circ}$; this value somewhat exceeds the typical width of the oval during quiet conditions, but it is intended to reflect the changing geographic latitude of the oval in the course of the day as well as the offset between the geographic and geomagnetic poles. The auroral particle ionization (Figure 5) adds significantly to the high-latitude values in magnetically conjugate hemispheres. The percentage ionization increase caused by auroral particle precipitation is greater in the winter hemisphere.

The calculated distribution of $\mathrm{N}\left({ }^{2} \mathrm{D}\right)$ for the case when auroral ionization is included is shown in Figure $2 b$. The effect of increased production of $N\left({ }^{2} D\right)$ in the auroral zone is clearly seen in magnetic conjugate hemispheres, but, as with the ionization source, the relative increase over the solarproduced $N\left({ }^{2} \mathrm{D}\right)$ distribution is greatest in the winter hemisphere. The $N\left({ }^{2} D\right)$ is assumed to be in photochemical equilibrium and is therefore affected only by changes in temperature and composition and not by the winds.

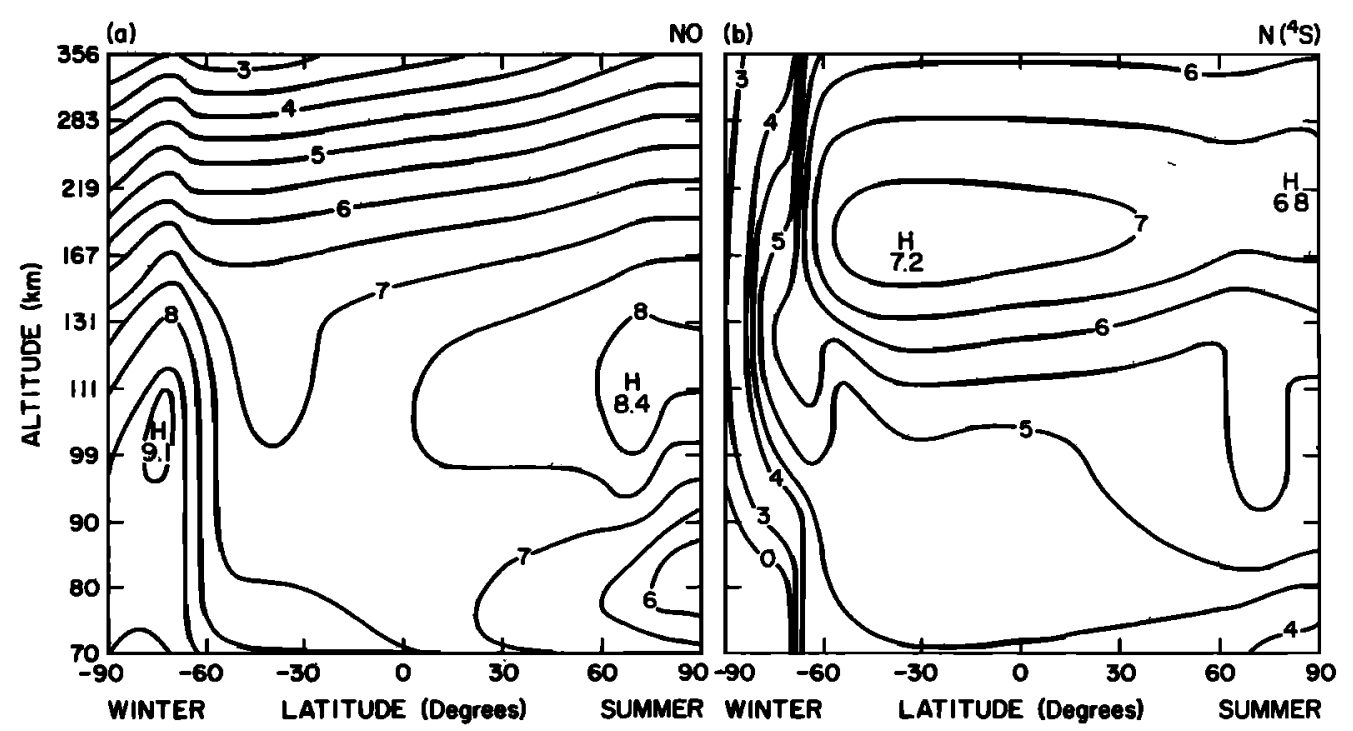

Fig. 6. Contours of $\log _{10}$ of zonally averaged densities of odd nitrogen $\left(\mathrm{cm}^{-3}\right)$ for solar and particle-induced ionization for quiet conditions: $(a)$ nitric oxide, $(b)$ atomic nitrogen. 


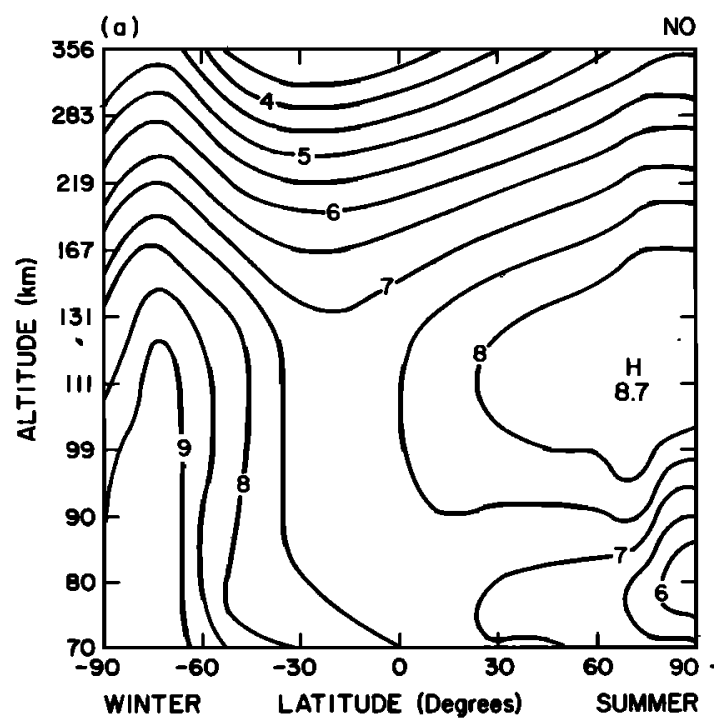

NO (b)

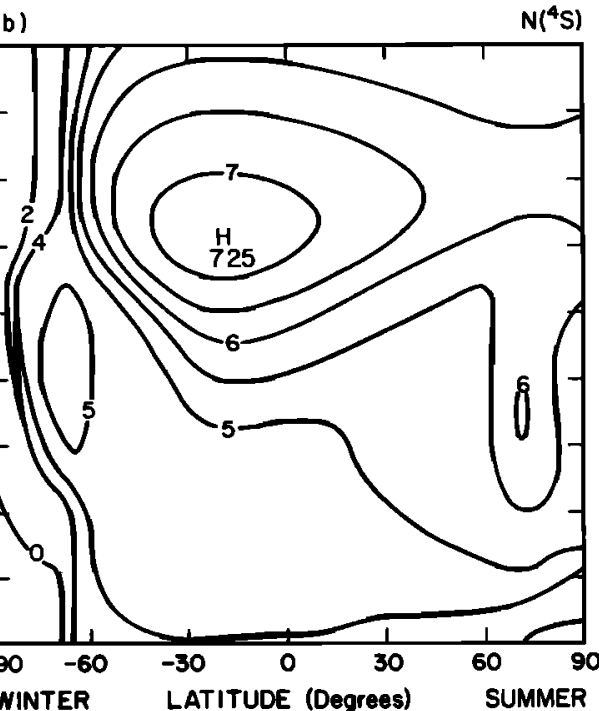

Fig. 7. Same as Figure 6, except for moderately disturbed conditions.

The calculated distributions for $\mathrm{NO}$ and $\mathrm{N}\left({ }^{4} \mathrm{~S}\right)$ for the aurora case and with winds included are shown in Figures $6 a$ and $6 b$, respectively. After 30 days of model integration time the NO densities have reached steady state, with the exception of minor changes at high latitudes below $90 \mathrm{~km}$. The effect of the aurora is to increase both the NO and $N\left({ }^{4} \mathrm{~S}\right)$ densities at high latitudes. In the summer hemisphere the NO density peaks near $110 \mathrm{~km}$ and $70^{\circ}$ latitude with a value of $2.4 \times 10^{8} \mathrm{~cm}^{-3}$, and in the winter hemisphere the peak is $10^{9} \mathrm{~cm}^{-3}$ at $90 \mathrm{~km}$ and $80^{\circ}$ latitude. A comparison of Figures $4 a$ and $6 a$ shows that auroral particle precipitation effectively increases the NO densities at all altitudes in the highlatitude thermosphere. It can also be seen that the summerto-winter meridional winds transport NO equatorward in the summer hemisphere. The NO densities decrease uniformly in latitude from the summer pole to about $40^{\circ}$ latitude in the winter hemisphere. The NO densities build up poleward of $-40^{\circ}$ latitude as a result of auroral particle precipitation. The effect of winds and vertical eddy diffusion in the polar night region of the winter hemisphere is to transport NO downward toward the mesosphere. This is consistent with the results of Solomon et al. [1982a] and Garcia and Solomon [1983], which showed that NO is transported from the thermosphere to the mesosphere and stratosphere in the polar night region. The NO vertical density profile in the polar night region is quite broad, similar to the high-latitude winter profile of NO determined by Swider [1978] from ion composition measurements. In the summer lower thermosphere the NO densities are similar for the two cases, except in the auroral zone, where there is particle production. This indicates that horizontal transport at this level is relatively small and that the NO densities are controlled by photodissociation.

The $\mathrm{N}\left({ }^{4} \mathrm{~S}\right)$ distribution shown in Figure $6 b$ reveals a complex latitudinal structure. Above about $150 \mathrm{~km}$, in the summer polar region, the $\mathrm{N}\left({ }^{4} \mathrm{~S}\right)$ density decreases relative to case $a$ shown in Figure $4 b$. The lower density is due to photochemistry resulting from temperature and compositional changes in the background gas, since $N\left({ }^{4} S\right)$ is in photochemical equilibrium in this region. The maximum $\mathrm{N}\left({ }^{4} \mathrm{~S}\right)$ density of $1.7 \times 10^{7} \mathrm{~cm}^{-3}$ occurs at $40^{\circ}$ latitude in the winter hemisphere at about $180 \mathrm{~km}$. The $\mathrm{N}\left({ }^{4} \mathrm{~S}\right)$ density of about $10^{7} \mathrm{~cm}^{-3}$ near $200 \mathrm{~km}$ in the summer hemisphere is consistent with the values derived by Engebretson et al. [1977a]. Compared to case $a$, there are also greater $\mathrm{N}\left({ }^{4} \mathrm{~S}\right)$ densities in the polar night region of the lower thermosphere as a result of particle precipitation. In the upper thermosphere, however, the meridional wind reverses and blows from the winter-to-summer pole in a region that extends from the pole to $60^{\circ}$ latitude in the winter hemispheres. This transports $\mathbf{N}\left({ }^{4} \mathbf{S}\right)$ equatorward out of the polar region, and the $N\left({ }^{4} S\right)$ density develops a sharp latitudinal density gradient in the region where the oppositely directed meridional circulations (Figure $4 a$ of R-K) meet. The N $\left({ }^{4} S\right)$ latitudinal distribution and densities in the upper thermosphere are consistent with the zonally averaged values of atomic nitrogen derived from the empirical model of Engebretson et al. [1977b]. The vertical velocities, meridional winds, temperature and compositional changes, and particle precipitation all combine to produce a complex $\mathrm{N}\left({ }^{4} \mathrm{~S}\right)$ structure in the winter polar region, as seen in comparing Figures $4 b$ and $6 b$.

\section{c. Solar EUV and Moderate Auroral Ionization}

R-K also calculated the circulation, temperature, and compositional structure for assumed moderate levels of geomagnetic activity. They multiplied the geomagnetic quiet time Joule and particle heat source by a factor of 3 , and their results are presented in Figures 6 and 7 of R-K. Using these background properties and multiplying our auroral ionization source by 3 , we run the model for 8 days; the calculated $\mathrm{NO}$ and $\mathrm{N}\left({ }^{4} \mathrm{~S}\right)$ distributions are shown in Figures $7 a$ and $7 b$, respectively. Comparing Figures $6 a$ and $7 a$, it can be seen that the enhanced ionization rate increases the high-latitude NO density. In these calculations the thermospheric NO reaches a maximum of $4 \times 10^{8} \mathrm{~cm}^{-3}$ near $110 \mathrm{~km}$ at summer high latitudes and $1 \times 10^{9} \mathrm{~cm}^{-3}$ in winter high latitudes. The location of the latitudinal minimum in the winter hemisphere has shifted equatorward by about $10^{\circ}$. This shift is caused by the increase of the high-latitude, particle-induced production of $\mathrm{N}$, by the development and equatorward displacement of the boundary of the reverse meridional wind cell, and by the change in the $\mathrm{O} / \mathrm{O}_{2}$ ratio caused by a global redistribution of 


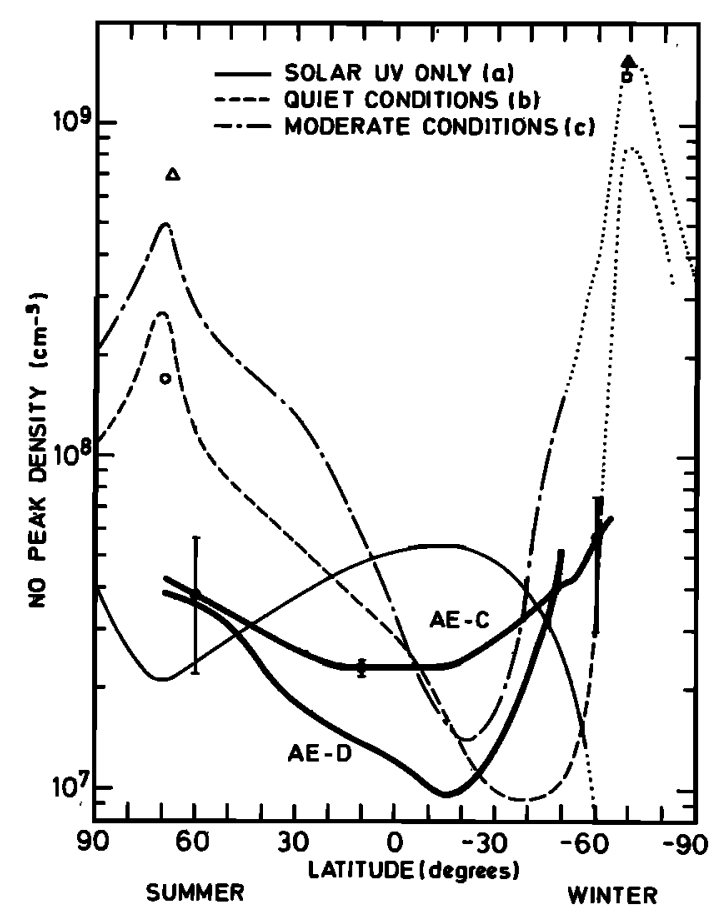

Fig. 8. Latitudinal distribution of the nitric oxide thermospheric peak density measured with the Atmospheric Explorer C and D satellites. Results of model calculations for quiet and moderate activity conditions are plotted for comparison. The dotted lines indicate regions where no NO thermospheric peak exists in the model. High-latitude nitric oxide peak densities deduced from rocket measurements of ion composition are also indicated: open circle, June 10, 1975; open triangle, August 18, 1974; open rectangle February 21, 1976; filled triangle January 15, 1977 [Arnold, 1980].

dynamics in the thermosphere in response to the higher highlatitude heating rate. In general, the effects generated in case $b$ by the addition of high-latitude heating and particle ionization are amplified in this case. The latitudinal gradient of nitric oxide in the lower thermosphere is also enhanced in comparison to the low-activity case. In the dark polar region the NO density increases at every latitude, and the vertical distribution remains nearly altitude-independent below 120 $\mathrm{km}$, in the vicinity of the terminator.

Comparison of Figures $6 b$ and $7 b$ shows that the $N\left({ }^{4} S\right)$ peak is still about $2 \times 10^{7} \mathrm{~cm}^{-3}$, but it has shifted equatorward with respect to case $b$. As for NO, the changes in the distribution of $\mathrm{N}\left({ }^{4} \mathrm{~S}\right)$ are caused mainly by the enhancement of the particle-induced $\mathrm{N}\left({ }^{4} \mathrm{~S}\right)$ production at high latitudes and by the compositional changes generated by changes of the circulation pattern in response to the level of energy deposited at high latitudes. The small increase of $\mathrm{N}\left({ }^{4} \mathrm{~S}\right)$ at low latitudes in response to greater high-latitude heating is consistent with the observation of Engebretson et al. [1980] and Engebretson and Mauersberger [1983].

\section{Comparison with ObServations}

The latitudinal distribution of the lower thermospheric NO densities has been investigated in detail with the UVNO experiment on the Atmospheric Explorer C and D satellites. Therefore, the AE results reported by Cravens and Stewart [1978] and Stewart and Cravens [1978] provide the best data for comparison with the model calculations. Figure 8 shows the comparison between the latitudinal gradient of the NO maximum density measured by AE and that calculated here.
We have adopted the curve, labeled group B by Cravens and Stewart, that was obtained by averaging measurements obtained by AE-C between days 212 and 249 and for which the mean $A p$ index was 23 . These orbits are the nearest to solstice conditions. The bars indicate the standard deviation of the measured NO density. We have also plotted the distribution of $\mathrm{NO}$ in the thermosphere as measured by the AE-D satellite (T. E. Cravens, M. Lecompte, and A. I. Stewart, private communication, 1982). The AE-D data were collected near solstice between December 1975 and February 1976. During this period of solar minimum activity, the average magnetic activity was fairly low. The AE-D orbit was polar and nearly sun-synchronous, and the measurements were gathered during morning hours. The latitudinal gradient in the AE-D observations is more pronounced than with $\mathrm{AE}-\mathrm{C}$ and extends to higher latitudes. The NO peak density exhibits a minimum near $20^{\circ}$ in the winter hemisphere and shows a steeper gradient toward the winter than the summer pole. With both satellites the latitudinal coverage is limited to the sunlit atmosphere as a consequence of the resonance scattering technique used to measure nitric oxide. The NO peak densities calculated for cases $a, b$, and $c$ are plotted for comparison. The latitudinal gradient calculated in model $a$ (solar driven winds, temperature, and composition-Figure 4) shows a maximum near the equator and minima near $60^{\circ}$ in both hemispheres. An equatorial maximum was also produced in the model calculations by $\mathrm{Cra}$ vens et al. [1979] and Gérard et al. [1980] for equinox conditions and by Rusch et al. [1981] for solstice conditions, although other composition and wind models were used in those studies. This pattern is opposite to the measured gradient and is not even observed, except under very quiet magnetic conditions when the NO near $105 \mathrm{~km}$ shows a slight equatorial bulge.

The distributions from cases $b$ (quiet magnetic conditions, Figure 6) and $c$ (moderate magnetic activity, Figure 7) are also plotted in Figure 8. Since the NO density peak is loosely defined or nonexistent in Figures $3 a, 4 a, 6 a$, and $7 a$ poleward of $50^{\circ}$ in the winter hemisphere, the density at $105 \mathrm{~km}$ is used in this plot for these regions. The distributions for cases $b$ and $c$ are quite different from case $a$ but not significantly different from each other. The most conspicuous difference is the value of the peak densities in the auroral zones and the steeper rise at winter mid-latitudes in case $c$. It is clear that the models that include the effects of particle precipitations yield a latitudinal distribution more closely resembling observations than that of the solar-driven model. The major discrepancies are the precise location of the low-latitude dip as well as the absolute densities in the summer hemisphere. These differences should not be considered as significant in this study, which is mostly concerned with the main features of the global NO distribution. It is likely that minor changes in the eddy diffusion coefficient field and/or undetermined chemical parameters would still improve the agreement between models and observations, but this problem lies outside the scope of this study. Furthermore, the AE observations were not made exactly at solstice nor in the same magnetic conditions as the models. The model calculations describe a near steady state, which may not describe accurately the average of a succession of quiet and disturbed periods. More importantly, the AE observations are limited to daytime, whereas the present model represents diurnal average densities. The diurnal variation of NO in the thermo- 


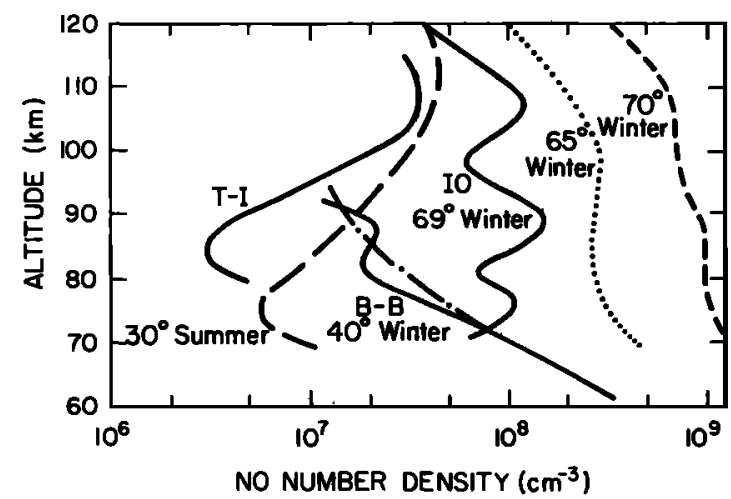

Fig. 9. Vertical distribution of nitric oxide measured with rockets in solstice conditions at various latitudes. Solid lines indicate measured distributions by Tohmatsu and Iwagami [1976] (T-1), Beran and Bangert [1979] (B-B), and Iwagami and Ogawa [1980] (1O). The calculated profiles for case $b$ are shown at $30^{\circ}$ summer (dashed line); $40^{\circ}$ winter (dashed and dotted line); $65^{\circ}$ winter (dotted line); and $70^{\circ}$ winter (short-dashed line) for comparison.

sphere was recently investigated by Rusch and Sharp [1981]. The magnitude of this variation is latitude-dependent and restricts the comparison with observations to trends rather than absolute values. The Atmospheric Explorer NO densities at high latitudes are smaller than those calculated for cases $b$ and $c$ with the model. They are also smaller than the bulge of nitric oxide densities derived in the auroral zones from ion composition data [Swider and Narcisi, 1977; Arnold, 1980] and rocketborne ultraviolet spectrometer data [Iwagami and Ogawa, 1980]. The four NO peak densities measured during solar minimum conditions are shown in Figure 8. These rocketborne ion spectrometer measurements were made near solstice in Northern Europe. They give NO densities between $1.7 \times 10^{8}$ and $7 \times 10^{8} \mathrm{~cm}^{-3}$ in summer, in better agreement with the two-dimensional calculations than the $\mathrm{AE}$ values. Winter densities are between $1.4 \times 10^{9}$ and $1.5 \times 10^{9} \mathrm{~cm}^{-3}$, very close to the results of the case $c$ calculation.

The fair agreement between models and observations for very quiet conditions on one hand and quiet or moderately disturbed conditions on the other hand clearly indicates the need for high-latitude heat and ionization sources during even fairly quiet magnetic conditions. The thermospheric NO maximum in the auroral zones is caused by the enhanced production of odd nitrogen in the regions subject to particle precipitation, as was previously established by various studies. This model demonstrates that the dynamical effects that control the background composition and the temperature also affect the NO distribution equatorward and poleward of the auroral zone. Figure 9 illustrates the comparison between three nitric oxide density profiles measured with rockets at the solstice period and at different latitudes. They were selected to represent typical distributions in solar minimum conditions and exhibit fairly characteristic differences in the shape of their distributions below $110 \mathrm{~km}$. They were obtained during fairly magnetically quiet conditions. The summer profile measured by Tohmatsu and Iwagami [1975] in August 1973 was obtained at $31^{\circ}$ north $(A P=9)$. The thermospheric peak reaches about $3 \times 10^{7} \mathrm{~cm}^{-3}$ at 108 $\mathrm{km}$. This distribution shows the density dip in the mesosphere typical of other summer profiles and is very similar to the equinox distribution measured at mid-latitude by Baker et al. [1977] or near the equator by Tohmatsu and Iwagami [1976].

A winter mid-latitude profile was obtained by Beran and Bangert [1979] on January 4, 1976, at $38^{\circ} \mathrm{N}(A p=10)$. This profile shows a loosely defined maximum near $87 \mathrm{~km}$, a weak mesospheric dip, and mesospheric densities larger than the summer profile by Tohmatsu and Iwagami [1975]. The density in the mesospheric valley near $85 \mathrm{~km}$ is about five times larger than the summer profile of Tohmatsu and Iwagami [1975].

The third distribution in Figure 9 was measured by Iwagami and Ogawa [1980] on August 10, 1977, at $69^{\circ} \mathrm{S}(\mathrm{AP}=$ 12). This high-latitude winter profile is quite different from the other two experimental curves and other lower-latitude measurements. It essentially shows a nearly constant density of $1 \times 10^{8} \mathrm{~cm}^{-3}$ between 70 and $100 \mathrm{~km}$, with a rather moderate peak near $89 \mathrm{~km}$. It is very likely that the particular shape of this curve is a consequence of the fact that it was measured in the winter auroral zone.

The three vertical distributions calculated with the model for quiet magnetic conditions and using Ebel's eddy coefficients (Figure $1 a$ ) are plotted in Figure 9 for the same latitude as the experimental profiles.

\section{DISCUSSION}

The results described earlier clearly demonstrate that the odd nitrogen distribution is controlled by various factors. It has been shown from a comparison of the NO density fields given in Figures 3, 4, 6, and 7 that the neutral winds, the atmospheric composition and temperature, and the level of particle-induced ionization control the nitric oxide distribution in a complex manner. The eddy diffusion coefficent $K$, formally defined in (4), also plays a significant role in controlling the NO distribution. Eddy diffusion becomes the major process for vertical transport below the turbopause where vertical winds have low velocities in our model. Consequently, eddy diffusion regulates the downward transport of NO from the thermosphere into the mesosphere and eventually to the stratopause. All three cases modeled so far were treated by using Ebel's [1980] grid of $K_{z z}$ values contained in Figure $1 a$. To investigate the sensitivity of the model to the choice of $K$, the calculations described before were repeated with the set of eddy diffusion coefficients used by R-K. As described by R-K, their coefficients were based on the vertical profile determined from the one-dimensional study of Allen et al. [1981], with an additional termconstant with altitude and Gaussian in latitude-added to maximize at the equator (Figure $1 b$ ). These coefficients were needed to maintain the atomic oxygen concentration and calculated 555.7-nm green-line emission rate at the observed values. When the Ebel [1980] coefficients were used in the calculation, atomic oxygen recombined at a too rapid rate, allowing the calculated densities to fall below the observed values. This difference in the eddy diffusion coefficients for NO and O was noted by Solomon et al. [1982a]. Schoeberl et al. [1983] recently found that the vertical eddy diffusion coefficients for NO and $\mathrm{O}$ are sensitive functions of their respective chemical loss rates in the mesosphere and lower thermosphere, thus accounting for the different $K$ values needed to model these species. Figure 11 shows the nitric oxide distribution calculated with the R-K $K$ coefficient for the case of quiet magnetic conditions (case $b$ ). Only small differences are seen in the summer thermosphere. However, 


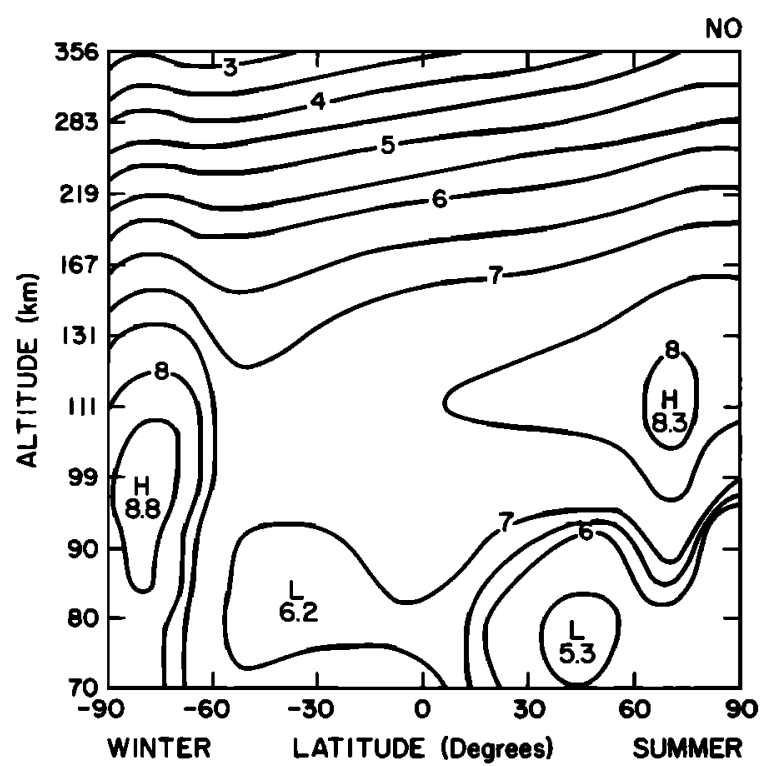

Fig. 10 Same as Figure 6, except that the eddy diffusion coefficients are those taken for Roble and Kasting [this issue] and contoured in Figure $1 b$.

with the modified $K$ 's the summer densities near the mesospheric valley are now in the range $2 \times 10^{5}$ to $10^{6} \mathrm{~cm}^{-3}$. Such values are unacceptably low when compared to the observational results shown in Figure 9 and other rocket measurements. The experimental data for summer and winter conditions, recently reviewed by Solomon et al. [1982a], are on the order of a new times $10^{6} \mathrm{~cm}^{-3}$ near $85 \mathrm{~km}$ for summer and fall. The mesospheric densities calculated by using Ebel's coefficients ranged from about $1 \times 10^{6} \mathrm{~cm}^{-3}$ at $60^{\circ}$ to about $2 \times 10^{7} \mathrm{~cm}^{-3}$ at the equator, in better agreement with the observations. In the winter hemisphere the most conspicuous differences are seen in the polar night region. With both sets of $K$ 's the vertical profiles are very flat in the vicinity of the terminator. A maximum of about $6 \times 10^{8} \mathrm{~cm}^{-3}$ is seen at $98 \mathrm{~km}$, at about $-80^{\circ}$ latitude as shown in Figure 10 and the vertical gradient below this peak is small. If the eddy diffusion coefficients of Ebel are used, the downward flux of NO is larger, and in the absence of photodissociation, nitric oxide piles up near the lower boundary.

Table 2 lists the downward flux of $\mathrm{NO}$ at different latitudes and altitudes calculated with this model for cases $a, b$, and $c$. The contours for cases $a$ and $b$ are shown in Figure 11. These represent diurnally averaged values, but actually the flux varies with local time, especially at high latitudes. It is also expected that both the particle and the solar EUV ionization and dissociation exhibit large variations with solar activity. These values are only typical of solar minimum conditions and fairly quiet magnetic activity.

In conclusion it has been shown that the calculated NO distribution in the lower thermosphere for the case of solar production alone does not agree with the observed latitudinal distribution. Better agreement is obtained when the ionization and dissociation sources of $\mathrm{N}_{2}$ caused by auroral particle precipitation are included in the calculations. The NO distribution in the lower thermosphere and mesosphere is sensitive to the value of the eddy diffusion coefficient used; the modified values of Allen et al. [1981], given by R-K and giving good agreement between calculated and observed values of atomic oxygen; and the Ebel [1980] coefficients giving good agreement for nitric oxide. This difference has been noted previously by Solomon et al. [1982a] and can be accounted for theoretically as discussed by Schoeberl et al. [1983]. To model the latitudinal distribution of NO, it is necessary to consider global dynamics and transport in a two- and, preferably, three-dimensional model. One-dimensional models, however, are still useful for modeling the diurnal variation of NO, $\mathrm{N}\left({ }^{4} \mathrm{~S}\right)$, and $\mathrm{N}\left({ }^{2} \mathrm{D}\right)$, considereing solar production at low and mid-latitudes during quiet geomagnetic conditions when transport from the auroral region is small. Finally, the global distribution of NO has been shown to be coupled to the dynamic state of the thermosphere. It is necessary to self-consistently consider the temperature, wind, $\mathrm{O} / \mathrm{O}_{2}$, and $\mathrm{O} / \mathrm{N}_{2}$ ratio changes generated by a global dynamic adjustment to auroral processes when calculating the global NO distribution. We examined such an interaction by first calculating the global temperature, composition, and circulation changes caused by different solar and auroral forcings and then using these values for the calculation of the global NO, N( $\left.{ }^{4} \mathrm{~S}\right)$, and $N\left({ }^{2} \mathrm{D}\right)$ distributions. For solar minimum during quiet geomagnetic conditions this decoupling is probably valid. However, for solar maximum, and during geomagnetic storms, NO $5.3-\mu \mathrm{m}$ cooling may be an important radiative loss for the thermosphere [Kockarts, 1980], requiring that the global dynamics and the major and

TABLE 2. Downward Flux of NO

\begin{tabular}{|c|c|c|c|c|c|c|c|c|}
\hline \multirow[b]{2}{*}{ Model } & \multirow[b]{2}{*}{ Altitude, km } & \multicolumn{7}{|c|}{ Latitude, deg } \\
\hline & & \multicolumn{3}{|c|}{ Summer } & \multicolumn{4}{|c|}{ Winter } \\
\hline \multirow{5}{*}{$\begin{array}{l}\text { Solar UV only, } \\
\text { case } a\end{array}$} & & 90 & 60 & 30 & 0 & 30 & 60 & 90 \\
\hline & 110 & $1.7(8)$ & $1.6(8)$ & $3.5(8)$ & $5.5(8)$ & $4.2(8)$ & $9.4(7)$ & $5.5(7)$ \\
\hline & 100 & $2.1(7)$ & $3.8(7)$ & $1.5(8)$ & $3.9(8)$ & $3.6(8)$ & $8.0(7)$ & $7.2(7)$ \\
\hline & 90 & $1.5(6)$ & $6.3(6)$ & $5.7(7)$ & $2.5(8)$ & $3.1(8)$ & $7.1(7)$ & $1.1(8)$ \\
\hline & 80 & $3.8(4)^{*}$ & $3.4(5)$ & $1.6(7)$ & $1.3(8)$ & $2.4(8)$ & $6.6(7)$ & $1.7(8)$ \\
\hline \multirow{4}{*}{$\begin{array}{l}\text { Quiet conditions, } \\
\text { case } b\end{array}$} & 110 & $6.6(8)$ & $7.3(8)$ & $4.4(8)$ & $4.1(8)$ & $2.5(8)$ & $5.7(8)$ & $3.3(8)$ \\
\hline & 100 & $9.0(7)$ & $2.1(8)$ & $2.0(8)$ & $3.0(8)$ & $2.1(8)$ & $5.2(8)$ & $5.2(8)$ \\
\hline & 90 & $6.7(6)$ & $4.3(7)$ & $7.7(7)$ & $1.9(8)$ & $1.8(8)$ & $3.8(8)$ & $7.6(8)$ \\
\hline & 80 & $2.6(5)$ & $5.6(6)$ & $2.3(7)$ & $1.0(8)$ & $1.4(8)$ & $2.4(8)$ & $1.0(9)$ \\
\hline \multirow{4}{*}{$\begin{array}{l}\text { Moderately disturbed } \\
\text { condition, case } c\end{array}$} & 110 & $1.4(9)$ & $1.7(9)$ & $1.2(9)$ & $4.5(8)$ & $4.2(8)$ & $5.5(9)$ & $1.8(9)$ \\
\hline & 100 & $1.8(8)$ & $4.4(8)$ & $4.7(8)$ & $3.3(8)$ & $3.5(8)$ & $3.9(9)$ & $2.0(9)$ \\
\hline & 90 & $9.3(6)$ & $8.7(7)$ & $1.3(8)$ & $2.0(8)$ & $2.8(8)$ & $2.3(9)$ & $2.0(9)$ \\
\hline & 80 & $2.6(5)$ & $1.2(7)$ & $2.7(7)$ & $1.1(8)$ & $1.9(8)$ & $1.1(9)$ & $2.5(9)$ \\
\hline
\end{tabular}

NO in $\mathrm{cm}^{-2} \mathrm{~s}^{-1} ; 1.7(8)$ reads $1.7 \times 10^{8}$.

*Upward flux. 


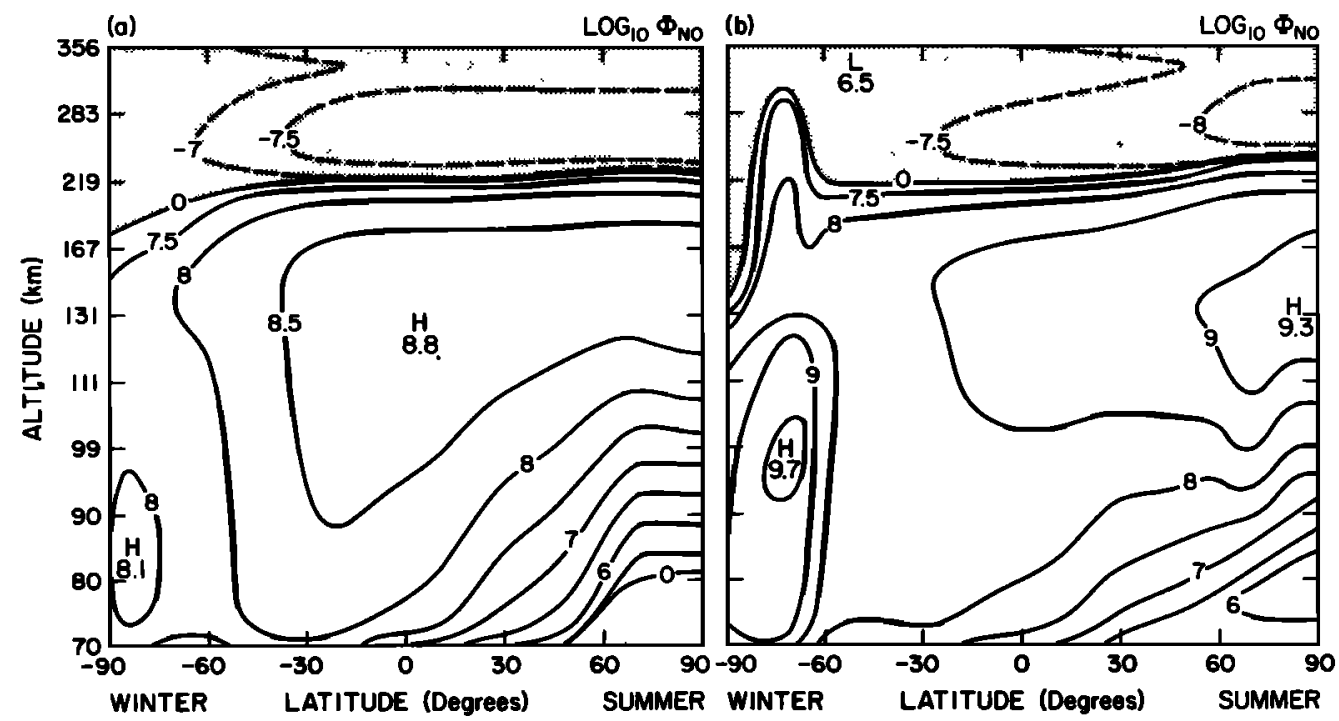

Fig. 11. Contours of $\log _{10}$ of the nitric oxide vertical flux $\left(\mathrm{cm}^{-2} \mathrm{~s}^{-1}\right)$ : $(a)$ case $a$, (b) case $b$. The shaded area indicates upward fluxes.

minor compositional and temperature structure be determined in a coupled manner with mutual interactions. Roble and Emery [1983], in a study of the global mean energy budget of the thermosphere above $130 \mathrm{~km}$, found that during solar minimum the solar EUV and UV energy absorbed is balanced by downward molecular thermal conduction. For solar maximum the energy absorbed by the thermosphere is not balanced by downward thermal conduction, but agreement between the calculated and observed temperatures is obtained with the inclusion of 5.3- $\mu \mathrm{m}$ radiational cooling by nitric oxide. Nitric oxide cooling is small during solar minimum because of low nitric oxide densities and low thermospheric temperatures, but it becomes significantly larger during solar maximum when nitric oxide densities and thermospheric temperatures are larger. Gordiets et al. [1982] also emphasizes the role of radiational cooling in determining the structure of the lower thermosphere. Therefore, to improve our understanding of the lower thermosphere, it is necessary to couple the dynamic, chemical, and radiational processes in a self-consistent manner such as in a merging of the dynamic model of R-K with the NO model presented in this paper.

Acknowledgments. This work was supported in part by NASA grant NAGW-292 to the University of Colorado. One of us (J.-C. G.) is supported by the Belgian Foundation for Scientific Research and FRFC grant 2-4507-82. We acknowledge the National Center for Atmospheric Research for computing time. NCAR is sponsored by the National Science Foundation. We acknowledge discussions with S. Solomon, M. H. Rees, B. A. Emery, and M. Callan and also mathematical help from J. Gary.

The Editor thanks H. G. Mayr and T. E. Cravens for their assistance in evaluating this paper.

\section{REFERENCES}

Allen, M., Y. L. Yung, and J. W. Waters, Vertical transport and photochemistry in the terrestrial mesosphere and lower thermosphere $(50-120 \mathrm{~km}), J$. Geophys. Res., 86, 3617, 1981

Arnold, F., The middle atmosphere ionized component, Proceedings of the ESA-PAC Symposium on European Rocket and Balloon Programmes and Related Research, Rep. ESA-SP-152, Eur. Space Agency, Neuilly, France, 1980.

Babcock, R. R., and J. V. Evans, Seasonal and solar cycle varia- tions in the thermospheric circulation observed over Millstone Hill, J. Geophys. Res., 84, 7348, 1979.

Baker, K. D., A. F. Nagy, R. O. Olsen, E. S. Oran, J. Randhawa, D. F. Strobel, and T. Tohmatsu, Measurement of the nitric oxide altitude distribution in the mid-latitude mesosphere, $J$. Geophys. Res., 82, 3281, 1977.

Barth, C. A., Rocket measurements of the nitric oxide dayglow, $J$. Geophys. Res., 69, 3301, 1964.

Beran, D., and W. Bangert, Trace constituents in the mesosphere and lower thermosphere during winter anomaly events, J. Atmos. Terr. Phys., 41, 1091, 1979.

Cravens, T. E., The global distribution of nitric oxide at $200 \mathrm{~km}, J$. Geophys. Res., 86, 5710, 1981.

Cravens, T. E., and A. I. Stewart, Global morphology of nitric oxide in the lower $E$ region, $J$. Geophys. Res., 83, 2446, 1978.

Cravens, T. E., J.-C. Gérard, A. I. Stewart, and D. W. Rusch, The latitudinal gradient of nitric oxide in the lower thermosphere, $J$. Geophys. Res., 84, 2675, 1979.

Crutzen, P. J., The role of NO and $\mathrm{NO}_{2}$ in the chemistry of the troposphere and stratosphere, Ann. Rev. Earth Planet. Sci., 7 , $443,1979$.

Dickinson, R. E., E. C. Ridley, and R. G. Roble, Meridional circulation in the thermosphere, 1, Equinox conditions, J. Atmos. Sci., 32, 1737, 1975.

Dickinson, R. E., E. C. Ridley, and R. G. Roble, Meridional circulation in the thermosphere, 2, Solstice conditions, J. Atmos. Sci., 34, 178, 1977.

Dickinson, R. E., E. C. Ridley, and R. G. Roble, A threedimensional general circulation model of the thermosphere, $J$. Geophys. Res., 86, 1499, 1981.

Donahue, T. M., E. C. Zipf, and T. D. Parkinson, Ion composition and ion chemistry in an aurora, Planet. Space Sci., 68, 171, 1970.

Ebel, A., Eddy diffusion models for the mesosphere and lower thermosphere, J. Atmos. Terr. Phys., 42, 617, 1980.

Emery, B. A., Neutral thermospheric winds deduced above Millstone Hill, 1, Mathematical model, uncertainties and representative results, J. Geophys. Res., 83, 5691, 1978a.

Emery, B. A., Neutral thermospheric winds deduced above Millstone Hill, 2, Seasonal wind variation, 1970-1971, J. Geophys. Res., 83, 5704, 1978b.

Engebretson, M. J., and K. Mauersberger, The response of thermospheric atomic nitrogen to magnetic storms, J. Geophys. Res., 88, 6331-6338, 1983.

Engebretson, M. J., K. Mauersberger, and W. E. Potter, Extension of atomic nitrogen measurements into the lower thermosphere, $J$. Geophys. Res., 82, 3291-3294, 1977a.

Engebretson, M. J., K. Mauersberger, D. C. Kayser, W. E. Potter, and A. O. Nier, Empirical model of atomic nitrogen in the upper thermosphere, J. Geophys. Res., 82, 461-471, $1977 b$.

Engebretson, M. J., J. A. DeFreese, and K. Mauersberger, Diurnal, 
seasonal, and nighttime variations of atomic nitrogen in the equatorial thermosphere, J. Geophys. Res., 85, 2165-2170, 1980.

Frederick, J. E., and R. D. Hudson, Predissociation of nitric oxide in the mesosphere and stratosphere, J. Atmos. Sci., 36, 737, 1979.

Frederick, J. E., and N. Orsini, The distribution and variability of mesospheric odd nitrogen: A theoretical investigation, J. Atmos. Terr. Phys., 44, 489, 1982.

Frederick, J. E., and D. W. Rusch, On the chemistry of metastable atomic nitrogen in the $F$ region deduced from simultaneous satellite measurements of the 5200- $\AA$ airglow and atmospheric composition, J. Geophys. Res., 82, 3508, 1977.

Frederick, J. E., R. B. Abrams, and P. J. Crutzen, The data band dissociation of nitric oxide: A potential mechanism for coupling thermospheric variations to the mesosphere and stratosphere, $J$. Geophys. Res., 88, 3829-3835, 1983.

Garcia, R. R., and S. Solomon, A numerical model of the zonally averaged dynamical and chemical structure of the middle atmosphere, J. Geophys. Res., 88, 1379-1400, 1983.

Geisler, J. E., and R. E. Dickinson, Vertical motions and nitric oxide in the upper mesosphere, J. Atmos. Terr. Phys., 30, 15051522, 1968.

Gérard, J.-C., and C. A. Barth, High-latitude nitric oxide in the lower thermosphere, J. Geophys. Res., 82, 674, 1977.

Gérard, J.-C. and D. W. Rusch, The auroral ionosphere: Comparison of a time-dependent model with composition measurements, J. Geophys. Res., 84, 4335, 1979.

Gérard, J.-C., R. G. Roble, and D. W. Rusch, A two-dimensional model of odd nitrogen in the thermosphere and mesosphere, Proceedings of the Fifth ESA Symposium on European Rocket and Balloon Programmes and Related Research, Bournemouth, UK, Rep. ESA SP 152, p. 55, Eur. Space Agency, Nevilly, France, 1980.

Goldan, P. D., A. L. Schmeltekopf, F. C. Fehsenfeld, H. l. Schiff, and E. E. Ferguson, Thermal energy ion-neutral reaction rate, 2, Some reactions of ionospheric interest, J. Chem. Phys., 44, 4095, 1966.

Golshan, N. and C. F. Sechrist, Seasonal and solar cycle variation of $E$ region nitric oxide, Radio Sci., 10, 305, 1975.

Gordiets, B. F., Yu N. Kulikov, M. N. Markov, and M. Ya. Marov, Numerical modeling of the thermospheric heat budget, $J$. Geophys. Res., 87, 4504, 1982.

Hernandez, G., and R. G. Roble, Direct measurements of nighttime thermospheric and temperature, 1, seasonal variations during geomagnetic quiet periods, J. Geophys. Res., 81, 2065, 1976a.

Hernandez, G., and R. G. Roble, Direct measurements of nighttime thermospheric and temperature, 2, Geomagnetic storms, $J$. Geophys. Res., 81, 5173, 1976 b.

Hinteregger, H. E., Representation of solar EUV fluxes for aeronomical applications, Adv. Space Res., I, 39, 1981.

Horvath, J. J., and C. J. Mason, Nitric oxide mixing ratios near the stratopause measured by a rocket-borne chemiluminescent detector, Geophys. Res. Lett., 5, 1023, 1978.

Hyman, E., D. J. Strickland, P. S. Julienne, and D. F. Strobel, Auroral NO concentrations?, J. Geophys. Res., 81, 4765, 1976.

Iwagami, N., and T. Ogawa, An antarctic NO density profile deduced from the gamma band airglow, Planet. Space Sci., 28, $867,1980$.

Kasting, J. F., and R. G. Roble, A zonally-averaged chemicaldynamical model of the lower thermosphere, J. Geophys. Res., 86, 9641, 1981.

Kley, D., G. M. Lawrence, and E. J. Stone, The yield of $N\left({ }^{2} D\right)$ atoms in the dissociative recombination of $\mathrm{NO}^{+}, \mathrm{J}$. Chem. Phys., 66, 4257, 1977.

Kockarts, G., Nitric oxide cooling in the terrestrial thermosphere, Geophys. Res. Lett., 7, 137, 1980.

Lin, C. L., and F. Kaufman, Reactions of metastable nitrogen atoms, J. Chem. Phys., 53, 3760, 1971.

Lindinger, W., F. C. Fehsenfeld, A. L. Schmeltekopf, and E. E. Ferguson, Temperature dependence of some ionospheric ionneutral reactions from $300^{\circ}$ to $900^{\circ} \mathrm{K}, J$. Geophys. Res., 79, 4753, 1974.

McFarland, M., D. L. Albritton, F. C. Fehsenfeld, E. E. Ferguson, and A. L. Schmeltekopf, Energy dependence and branching ratio of the $\mathrm{N}_{2}{ }^{+}+\mathrm{O}$ reaction, J. Geophys. Res. 79, 2925, 1974.

Mason, C. J., and J. J. Horvath, The direct measurement of nitric oxide concentration in the upper atmosphere by a rocket-borne chemiluminescent detector, Geophys. Res. Lett., 3, 391, 1976.
Massie, S. T., Nitric oxide delta band absorption measurements in the lower thermosphere, J. Geophys. Res., 85, 2155, 1980.

Meira, L. G., Rocket measurements of upper atmospheric nitric oxide and their consequences to the lower ionosphere, $J$. Geophys. Res., 76, 202, 1970.

NASA, Evaluation 2, Panel Data Eval. Chem. Kinet. Photochem. Data Use Stratospheric Model., Jet Propul. Lab., Publ. 27, Wash., D. C., 1979.

Narcisi, R. S., and W. Swider, Ionic structure near an auroral arc, $J$. Geophys. Res., 81, 4770, 1976.

Norton, R. B., and C. A. Barth, Theory of nitric oxide in the earth's atmosphere, J. Geophys. Res., 75, 3903, 1970.

Oliver, W. L., Improved Millstone Hill exospheric temperature measurements: Evidence for a seasonal variation of the magnetic activity effect, J. Geophys. Res., 85, 4237, 1980.

Oran, E. S., P. S. Julienne, and D. F. Stobel, The aeronomy of odd nitrogen in the thermosphere, J. Geophys. Res., 80, 3068, 1975.

Philips, L: F., and H. I. Schiff, Mass spectrometer studies of atom reactions, 1 , reactions in the atomic ozone system, J. Chem. Phys., 36, 1509, 1962.

Rees, M. H., and R. G. Roble, The morphology of N and NO in auroral substorms, Planet. Space Sci., 27, 453, 1979.

Roble, R. G., Solar EUV flux variation during a colar cycle as derived from ionospheric modeling considerations, J. Geophys. Res., 81, 265, 1976?

Roble, R. G., and B. A. Emery, On the global mean temperature of the thermosphere, Plant. Space Sci., 31, 597, 1983.

Roble, R. G., and J. M. Gary, The effect of horizontal transport on auroral NO densities, Geophys. Res. Lett., 6. 703, 1979.

Roble, R. G., and J. F. Kasting, The zonally averaged circulation, temperature, and compositional structure of the thermosphere and variations with geomagnetic activity, J. Geophys. Res., this issue.

Roble, R. G. and M. H. Rees, Time-dependent studies of the aurora: Effects of particle precipitation on the dynamic morphology of ionospheric and atmospheric properties, Planet. Space Sci., 25, 991, 1977.

Roble, R. G., R. E. Dickinson, and E. C. Ridley, Seasonal and solar cycle variations of the zonal circulation in the thermosphere, $J$. Geophys. Res., 82, 5493, 1977.

Rusch, D. W., Satellite ultraviolet measurements of nitric oxide fluorsecence with a diffusive transport model, J. Geophys. Res., 78, 5676, 1973.

Rusch, D. W. and C. A. Barth, Satellite measurements of nitric oxide in the polar region, J. Geophys. Res., 80, 3719, 1975.

Rusch, D. W., and J.-C. Gerard, Satellite studies of N( $\left.{ }^{2} \mathrm{D}\right)$ emission and ion chemistry in aurorae, J. Geophys. Res., 85, 1285, 1980.

Rusch, D. W., and W. E. Sharp, Nitric oxide delta band emission in the earth's atmosphere: comparison of a measurement and a theory, J. Geophys. Res., 86, 1011, 1981.

Rusch, D. W., A. I. Stewart, P. B. Hays, and J. H. Hoffman, The NI (5200 A) dayglow, J. Geophys. Res., 80, 2300, 1975.

Rusch, D. W., R. G. Roble, J.-C. Gérard, and A. I. F. Stewart, A two-dimensional model of odd nitrogen in the thermosphere and mesosphere, in Map Handbook, vol. 2, edited by S. K. Avery, p. 442,1981 .

Schoeberl, M. R., D. F. Strobel, and J. P. Apruzese, A numerical model of gravity wave breaking and stress in the mesosphere, $J$. Geophys. Res., 88, 5249, 1983.

Sechrist, C. F., A theory of the winter absorption anomaly at middle latitudes, J. Atmos. Terr. Phys., 29, 113, 1967.

Sharp, W. E., $\mathrm{NO}_{2}$ continuum in aurora, J. Geophys. Res., 83, 4373, 1978.

Singh, V., and J.-C. Gérard, The thermospheric heating efficiency under electron bombardment conditions, Planet Space Sci., 30 , $1083,1982$.

Solomon, S., One- and two-dimensional photochemical modeling of the chemical interactions in the middle atmosphere $(0-120 \mathrm{~km})$, Coop. thesis 62, Nat. Center Atmos. Res., Boulder, Colo., 1981.

Solomon, S., P. J. Crutzen, and R. G. Roble, Photochemical coupling between the thermosphere and the lower atmosphere, 1 , Odd nitrogen from 50 to $120 \mathrm{~km}, J$. Geophys. Res., 87, 7206, $1982 a$.

Solomon, S., G. C. Reid, R. G. Roble, and P. J. Crutzen, Photochemical coupling between the thermosphere and the lower atmosphere, $2, D$ region ion chemistry and the winter anomaly, $J$. Geophys. Res., 87, 7221, $1982 b$. 
Stewart, A. I., Photoionization coefficients and photoelectron impact excitation efficiencies in the daytime ionosphere, $J$. Geophys. Res., 75, 6333, 1970.

Stewart, A. I., and T. E. Cravens, Diurnal and seasonal effects in $E$ region low-latitude nitric oxide, J. Geophys. Res., 83, 2453, 1978.

Strobel, D. F., D. M. Hunten, and M. B. McElroy, Production and diffusion of nitric oxide, J. Geophys. Res., 75, 4307, 1970.

Swider, W., and R. S. Narcisi, Auroral $E$ region: Ion composition and nitric oxide, Planet. Space Sci., 25, 103, 1977.

Swider, W., Daytime nitric oxide at the base of the thermosphere, $J$. Geophys. Res., 83, 4407, 1978.

Thomas, R. J., A high-altitude rocket measurement of nitric oxide, J. Geophys. Res., 83, 513, 1978.

Tisone, G. C., Measurements of NO densities during sunrise at Kauai, J. Geophys. Res., 78, 746, 1973.

Tohmatsu, T., and N. Iwagami, Measurement of nitric oxide distribution in the upper atmosphere, Space Res., 45, 241, 1975.

Tohmatsu, T., and N. Iwagami, Measurement of nitric oxide abundance in equatorial upper atmosphere, J. Geomagn. Geoelec. Jpn., 28, 343, 1976.

Torr, D. G., J. C. G. Walker, L. H. Brace, J. H. Hoffman, A. O. Nier, and M. Oppenheimer, Recombination of $\mathrm{NO}^{+}$in the ionosphere, Geophys. Res. Lett., 3, 209, 1976.
Trinks, H., U. von Zahn, C. A. Barth and K. K. Kelly, A joint nitric oxide measurement by rocket borne ultraviolet photometric and mass spectrometer in the lower thermosphere, J. Geophys. Res. $83,203,1978$

Witt, G., J. Rose, and E. J. Llewellyn, The airglow continuum at high latitudes-An estimate of NO concentration, J. Geophys. Res. 86, 623, 1981.

Zipf, E. C., P. J. Espy, and C. F. Boyle, The excitation and collisional deactivation of metastable $\mathrm{N}\left({ }^{2} \mathrm{P}\right)$ atoms in auroras, $J$. Geophys. Res., 85, 687, 1980.

J.-C. Gerard, Institut d'Astrophysique, Université de Liège, 4200 Liège, Belgium.

R. G. Roble, National Center for Atmospheric Research, P. O. Box 3000, Boulder, CO. 80307.

D. W. Rusch and A. I. Stewart, Laboratory for Atmospheric and Space Physics, University of Colorado, Boulder, CO 80303.

(Received February 22, 1983;

revised October 31, 1983;

accepted November 2, 1983.) 